\title{
TDP-43: A KEY THERAPEUTIC TARGET BEYOND AMYOTROPHIC LATERAL SCLEROSIS
}

\author{
Valle Palomo, ${ }^{1,2}$ Carlota Tosat-Bitrian, ${ }^{1}$ Vanesa Nozal, ${ }^{1}$ Siranjeevi Nagaraj, ${ }^{1,3}$ Angeles \\ Martin-Requero, ${ }^{1,2 *}$ and Ana Martinez, ${ }^{1,2 *}$ \\ ${ }^{1}$ Centro de Investigaciones Biologicas-CSIC, Ramiro de Maeztu 9, 28040 Madrid \\ (Spain). \\ ${ }^{2}$ Centro de Investigación Biomédica en Red de Enfermedades Neurodegenerativas \\ (CIBERNED), Instituto Carlos III (Spain). \\ ${ }^{3}$ Present address: Laboratory of Preclinical Testing of Higher Standard, Nencki \\ Institute of Experimental Biology, Polish Academy of Science, Pasteur 3 St., 02-093 \\ Warsaw (Poland).
}

Correspondence to:

Prof. Ana Martinez

e-mail: ana.martinez@csic.es

ORCID iD: 0000-0002-2707-8110

Dr. Angeles Martin-Requero

e-mail: amrequero@cib.csic.es

ORCID iD: 0000-0002-3416-9440 


\section{ABSTRACT (250 WORDS)}

Accumulation of TDP-43 in the cytoplasm of diseased neurons is the pathological hallmark of Frontotemporal Dementia-TDP (FTLD-TDP) and Amyotrophic Lateral Sclerosis (ALS), two diseases that lack of efficacious medicine to prevent or to stop disease progression. The discovery that mutations in the TARDBP gene (coding for the nuclear protein known as TDP-43) in both FTLD and ALS patients provided evidence for a link between TDP-43 alterations and neurodegeneration. The knowledge of TDP43 function has advanced profoundly in the last years, however its complete role and the molecular mechanisms that lead to disease have yet to be fully understood. Here we summarize the recent studies of this protein, its relation to neurodegenerative diseases and the therapeutic strategies to restore its homeostasis with small molecules. Finally, we briefly discuss the available cellular and animal models that help to shed light on TDP-43 pathology and could serve as tools to discover pharmacological agents for the treatment of TDP-43 related diseases.

KEY WORDS: TDP-43, ALS, FTLD, drug discovery,

\section{INDEX}

1. Introduction

2. Biology and pathophysiological function of tdp-43

2.1 Regulation of TDP-43 levels

2.2 Pathological modifications of TDP-43

3. Modulation of TDP-43 proteostasis by small molecules

3.1 Protein kinase inhibitors

3.2 Inhibitors of stress granules

3.3 Autophagy modulators

3.4 Other TDP-43 modulators

4. Cellular and animal models to evaluate TDP-43 homeostasis

5. Conclusions

\section{ABBREVIATIONS LIST:}

$A D$, Alzheimer's disease; ALS, amyotrophic lateral sclerosis; CDC7, cell division cycle kinase 7; CDK6, cyclin dependent kinase 6; CNS, central nervous system; CK-1, casein kinase 1; DLB, dementia with Lewy bodies; EA, ethacrynic acid; FDA, Food and Drug Administration; FL, full-length ; FTLD, frontotemporal lobar dementia; FUS, fused in sarcoma protein; GSK-3, glycogen synthase kinase 3; HD, Huntington's disease; 
iPSCs, induced pluripotent stem cells; MAPK/ERK, mitogen-activated protein kinases; Mfn1, mitofusin 1; MQC, mitochondrial quality control; MSA, multiple system atrophy; MSP, multisystem proteinopathy; mTOR, mammalian target of rapamycin; NLS, nuclear localization signal; NMD, non-sense-mediated decay; PD, Parkinson's disease; PGRN, progranulin; PPARy, Peroxisome proliferator-activated receptor gamma PSP, progressive supranuclear palsy; SG, stress granules; SMA, spinal muscular atrophy; SOD, superoxide dismutase; TDP-43, TAR DNA-binding protein of $43 \mathrm{KD}$; TTBK1, tau tubulin kinase 1; hUPF1, human up-frameshift protein 1; UPS, ubiquitin-proteasome system (UPS); wt, wild type; XPO1, nuclear receptor exportin-1. 


\section{Introduction}

The term proteinopathy refers to a number of neurodegenerative disorders characterized by the accumulation of specific proteins in the central nervous system (CNS). ${ }^{1}$ Typically, these proteins are unstructured and monomeric in the healthy brain, while under pathological conditions, they undergo conformational changes leading to oligomers formation that eventually turn into aggregated structures. These changes result in the gain of new toxic function and/or the loss of the physiological function.

Many factors may affect the conformational stability of aggregation-prone proteins. First, mutations in the structural regions of the genes coding for such proteins may change their physico-chemical properties. ${ }^{2}$ In other cases, mutations in the regulatory regions of the coding genes may increase their transcription. Increased concentration of the protein may facilitate the formation of aggregates. ${ }^{3}$ Other factors affecting the initiation of pathogenic aggregation include age, oxidative stress, virus infection, metal ions and chronic inflammation. 4,5 Moreover, the interaction of these proteins in aberrant conformation with other molecules may spread the pathogenic changes in a prion-like manner. ${ }^{6}$ Finally, it is also known that post-translational modifications play an important role in pathogenic aggregation. ${ }^{7}$

Proteinopathies are grouped by the nature of the major protein found in the aggregates. The so-called amyloidosis comprises a number of diseases in which the inclusions have amyloid properties exhibiting positive congo red staining and fibrillary structure. ${ }^{8}$ The most prominent disorder in this group is Alzheimer's disease (AD) characterized by the presence of $A \beta$ amyloid plaques. Taupathies encompass several disorders characterized by the presence of insoluble deposits of microtubuleassociated tau protein. They are associated with dementia or degeneration of the motor system, and are found in $A D$, progressive supranuclear palsy (PSP) or frontotemporal lobular degeneration (FTLD-TDP). ${ }^{9}$

The term synucleinopathies is used to name a group of neurodegenerative disorders characterized by fibrillary aggregates of alpha-synuclein protein in a selective population of neuronal and glial cells. ${ }^{10}$ These disorders include Parkinson's disease (PD), dementia with Lewy bodies (DLB), pure autonomic failure (PAF), and multiple system atrophy (MSA).

Mutations in FUS (fused in sarcoma) and structural alterations of the FUS protein are considered one potential cause of ALS and FTLD. The presence of FUS-positive 
inclusions in affected neurons are typical for both ALS-FUS and FTLD-FUS, being the unifying feature of FUSopathies. ${ }^{11}$

A different type of proteinopathy comprises the so-called polyglutamine (polyQ) diseases, which are neurodegenerative disorders caused by expansion of unstable polyQ repeats in their associated disease proteins. Examples are Huntington's disease (HD), or spinocerebellar ataxia type $17 . .^{12}$

TAR DNA-binding protein of 43 KD (TDP-43) was first identified in 2006. ${ }^{13}$ Since then, numerous studies confirmed the presence of this protein as the major component in the abnormal neuronal and glial inclusions observed in a number of neurodegenerative disorders grouped by the general term of TDP-43 proteinopathies. Prominent TDP-43 cytoplasmic mislocalization and aggregation are evident in amyotrophic lateral sclerosis (ALS) and FTLD-TDP, but also in Perry syndrome, Alexander disease, and multisystem proteinopathy (MSP). ${ }^{14}$ In addition, TDP-43 pathology is a secondary feature of several other neurodegenerative disorders, including AD, PD, and HD. ${ }^{15-17}$ It has been reported that its presence may aggravate the primary existing proteinopathy. ${ }^{18}$ Lastly, TDP-43 pathology has also been observed in spinal muscular atrophy (SMA), and in infertile men. ${ }^{19,} 20$

While some of these diseases are characterized by a single type of protein aggregates, proteinopathies are often heterogeneous making a definite diagnosis difficult. The present work is focused on TDP-43 proteinopathies. We review current knowledge about TDP-43 physio-pathological functions and summarize the most promising avenues to modulate TDP-43 pathology based on already identified potential therapeutic targets.

\section{Biology and physiopathological functions of TDP-43}

TDP-43 is a highly conserved 414-amino acid nuclear protein. It is encoded by the TARDBP gene and it is ubiquitously expressed.21 TDP-43 contains two RNA recognition motifs, a nuclear localization sequence, a nuclear export signal, ${ }^{22}$ and a glycine-rich C-terminus that mediates protein-protein interactions. ${ }^{23}$ The majority of ALS causing mutations identified in human disease have been found in the $\mathrm{C}$-terminus of TDP-43, indicating that this region of the protein may mediate pathological protein modifications and aggregation. TDP-43 pre-dominantly resides in the nucleus, but is capable of nucleocytoplasmic shuttling. ${ }^{22}$

The knowledge of physiopathological functions of TDP-43 is still incomplete. This 
protein plays a variety of roles in RNA metabolism, including transcription, splicing, mRNA transport, mRNA stability through recruitment into stress granules (SGs), and microRNA biosynthesis. ${ }^{24}$ Recently, it has been described that, in contrast to other RNA-binding proteins that regulate splicing of conserved exons, TDP-43 repressed the splicing of non-conserved cryptic exons, and that this process is impaired in ALS-FTLD cases. ${ }^{25}$ The TDP-43 repressed cryptic exons are cell-type specific and different pathways may be altered, which may have mechanistic and therapeutic implications in the TDP-43 proteinopathies spectrum. ${ }^{26}$ Moreover, TDP-43 seems to be involved in miRNA biogenesis. ${ }^{27}$ miRNAs are short non-coding RNA molecules (19-24 nucleotide long) that mediate epigenetic regulation of gene expression, mainly at the posttranscriptional level. ${ }^{28}$ Emerging evidences indicate that down-regulated TDP-43 levels or the presence of mutant TDP-43 impair miRNA biogenesis in cellular models. ${ }^{29,} 30$ Apparently TDP-43 is required for the correct assembly of the pre-miRNA attached to Drosha protein and the cytoplasmatic Dicer protein to produce a mature 20-bp miRNA duplex intermediate. ${ }^{27}$

\subsection{Regulation of TDP-43 levels}

Given the number and variety functions in which TDP-43 is involved, it is not surprising that TDP-43 levels are tightly regulated. TDP-43 controls its own expression through a negative feedback loop. TDP-43 binds to the 3'-UTR of its mRNA, leading to nonsense-mediated decay (NMD)-independent mRNA degradation and a decrease in the cellular levels of TDP-43. The integrity of the TDP-43 C-domain in the region 321-366 seems to be necessary for this autoregulation. ${ }^{31}$ In addition, TDP-43 expression has also been shown to be regulated by miR-b2122. ${ }^{32}$

On the other hand, control of TDP-43 cellular levels could also occur at a posttranslational level, since changes in the TDP-43 protein half-life have been reported in different cell lines. ${ }^{33}$

The disruption of TDP-43 autoregulation may contribute to TDP-43 proteinopathy, as it was reported that TDP-43 overexpression in C. elegans, Drosophila or mouse is sufficient to increase the levels of endogenous TDP-43 and to induce neurodegeneration. ${ }^{34-36}$ Therefore, it seems that a treatment that keeps protein levels just right would be an attractive therapeutic approach. In this regard, the recent finding that manipulating cellular levels of human up-frameshift protein 1 (hUPF1), a master regulator of the protective NMD mechanism resulted in download of TDP-43 levels and enhanced neuronal survival ${ }^{37}$ opens an avenue for designing and developing new drugs that target this system to maintain normal levels of TDP-43 and protect neurons. 


\subsection{Pathological modifications of TDP-43}

The term TDP-43 proteinopathy describes the characteristic histopathological transformation of TDP-43 homeostasis in disease, namely the deposition of full-length and fragmented TDP-43 protein, ubiquitinated and hyperphosphorylated aggregates in the cytoplasm, associated with loss of TDP-43 in the nucleus. ${ }^{13}$ However, the mechanistic aspects leading to accumulation of pathological TDP-43 and functional consequences are not yet fully understood. It remains to be determined which of these events are triggering the development of the disease and which could be potential targets for therapeutic intervention (Figure 1).

\section{Here, Figure 1}

The key question of whether cytosolic TDP-43 accumulation implicates the gain of a new toxic function and/or the concomitant reduced TDP-43 nuclear levels represents the loss of its essential role, is still a matter of debate. There is evidence that loss of TDP-43 nuclear functions could have pathogenic influence. For example, we found nuclear loss of TDP-43 induced repression of CDK6 transcription in lymphoblasts from FTLD-TDP patients ${ }^{38}$ and a deficit in the TDP-43 splicing repressor of non-conserved cryptic exons have been detected in brain of FTLD/ALS individuals. ${ }^{25}$ Direct evidence for changes in more than 600 mRNAs in a murine model of ALS following TDP-43 nuclear depletion was obtained by using massively sequencing and splicing-sensitive junction arrays. ${ }^{39}$ Alternatively, generation and sequestration of abnormal TDP-43 species such as hyperphopshorylated TDP-43 C-terminal fragments in cytoplasmic inclusions might induce a toxic gain of function. The current consensus is that the disease likely arises from a combination of both loss and gain of TDP-43 functions. The balance between nuclear and cytosolic levels of TDP-43 appears to be controlled by both nuclear localization signal (NLS) and nuclear export signal motifs. ${ }^{22,} 40$ Alterations in the NLS motif in cell cultures were reported to induce cytoplasmic TDP-43 accumulation, associated with changes in TDP-43 solubility and reduced nuclear TDP43 levels. ${ }^{22}$ These observations suggest that perturbation of normal shuttling of TDP-43 between nucleus and cytoplasm can lead to the formation of TDP-43 aggregates that recapitulate features of TDP-43 signature lesions of FTLD-TDP and ALS.

The protein aggregates in TDP-43 proteinopathies contain TDP-43 extensively modified by post-translational mechanisms not observed in healthy neurons, including ubiquitination, acetylation, SUMOylation, and phosphorylation, ${ }^{13,41}$ the latter being the most consistent marker of pathological TDP-43 deposition. Specific sites of phosphorylation occur at the C-terminus of the molecule, predominantly at serines 409 
and 410 (S409/410). ${ }^{42}$ Phosphorylation at S409/410 has been shown to induce protein aggregation, neurotoxicity and neurodegeneration, decreased protein turnover and increased cytoplasmic accumulation. ${ }^{43}$

It has been described that cytosolic aggregates of TDP-43 can be classified in different classes of misfolded TDP-43 species based on their vulnerability to degradation by proteasome and autophagy and its mobility. Taking these features into account, six different classes of misfolded TDP-43 have been distinguished ${ }^{44}$ (Figure 2):

1) monomeric, highly mobile, proteasome-degradable TDP-43,

2) a fraction of aggregates, Agg1, possibly in equilibrium with the monomer and susceptible to proteasome degradation,

3) Agg2, oligomeric, slowly mobile, autophagy-degradable fraction of TDP-43 aggregates,

4) TDP-43 microaggregated inmobile and degradable by autophagy,

5) Agg3 non degradabled fraction of cytosolic TDP-43

6) macroaggregated immobile non degradable TDP-43.

Here, Figure 2.

Several kinases with ability to phosphorylate or modulate TDP-43 in vitro and in vivo have been identified so far, including casein kinase 1 (CK-1), ${ }^{45}$ cell division cycle 7 $(C D C 7),{ }^{46}$ tau and tubulin kinase 1 and 2 (TTBK1 and TTBK2), ${ }^{47}$ glycogen synthase kinase $3 \beta$ (GSK-3 $\beta)^{48}$ and mitogen-activated protein kinases (MAPK/ERK). ${ }^{49}$ All of these kinases may contribute to regulate TDP-43 phosphorylation in humans as all of them share target sequence conservation. Whether they act redundantly to promote TDP-43 phosphorylation in vivo, or there is specific kinase activation triggered by extra or intracellular signals is not yet known. On the other hand, it is worth mentioning that, it has been recently reported that the phosphatase calcineurin is able to dephosphorylate TDP-43. ${ }^{50}$ Calcineurin depletion in C. elegans results in accumulation of phosphorylated TDP-43, and enhanced motor dysfunction. Similar effects were found in human cultured cells following pharmacological inhibition of calcineurin.

Like other proteins that form intracellular inclusions, the pathological TDP-43 aggregates are ubiquitinated. It is thought that disruption of the ubiquitin-proteasome system (UPS) might contribute to increased levels of ubiquitinated TDP-43 in ALS and FTLD-TDP. ${ }^{51}$ Indeed, inhibition of the UPS leads to increased levels of phosphorylated TDP-43 aggregates in cultured cells. ${ }^{22}$ 
The findings that ALS-linked mutations in genes p62/SQSTM1, VCP, UBQL and OPT, coding for proteins involved in protein degradation (UPS- and autophagosomemediated degradation $)^{52}$ add further support to the idea that perturbation of protein degradation pathways is mechanistically linked to the formation of TDP-43 inclusions. p62 and VCP are required to form autophagosomes. ${ }^{53}$ This is the first step in the autophagy pathway; the autophagosome sequesters degradation targets and delivers them to lysosomes for degradation, a process orchestrated by a complex network of proteins encoded by ATGs. ${ }^{54}$ It is known that mutant TDP-43 impairs its ability to bind and stabilize ATG7 mRNA, thus leading to autophagy dysfunction. ${ }^{55}$ On the other hand, TDP-43 appears to regulate autophagy by affecting the localization and activity of the transcription factor TFEB, which results in altered expression of autophagy and lysosomal proteins. ${ }^{56}$ TDP-43 interacts with several proteins involved in autophagy, such as the endosomal sorting complexes required for transport, ${ }^{57}$ ubiquilin $1^{58}$ and sequestosome 1.59 Moreover TDP-43 seems to modulate the autophagosomelysosome fusion. ${ }^{56}$ Together, these findings support the idea that TDP-43 regulates autophagy, and thus regulates its own turnover. Conversely, it has been demonstrated that molecules able to activate the UPS or autophagy promote TDP-43 clearance and ameliorate toxicity in models based on TDP-43 overexpression 60,51 and they will be discussed in the next section.

TDP-43 has been shown to alter the so-called Mitochondrial Quality Control (MQC) system, which functions to assure the homeostasis of mitochondrial proteins. ${ }^{61}$ For example, a direct effect of TDP-43 on mitochondrial biogenesis in different cell models of ALS was recently demonstrated.62 Mutant or overexpressed TDP-43 appears to localize in the internal mitochondrial membrane.62 TDP-43 is also involved in mitochondrial dynamics, apparently by inducing the downregulation of mitofusin 1 (Mfn1). ${ }^{63}$ Interestingly, overexpression of Mfn1 in transgenic TDP-43 flies restores mitochondrial length and ameliorates and locomotor defects. ${ }^{61}$ TDP-43 could also play a role in mitophagy as several studies on patient tissues and murine models indicate that TDP-43 leads to abnormal aggregation of mitochondria in motor neurons that are reminiscent of mitochondria undergoing mitophagy. ${ }^{64}$ However contradictory results have been reported regarding the localization of autophagic markers in mitochondria. ${ }^{65}$ Further work is needed to definitely clarify the role of mitophagy in the pathogenesis of these proteinopathies. Should this happen, pharmacological agents should be designed to restore the MQC system and particularly mitophagy, as treatments of these diseases. 
From the above considerations, it seems obvious that alterations of protein TDP-43 homeostasis have many downstream consequences that contribute to the neurodegenerative process. ${ }^{66}$ Understanding the specific features of protein imbalance is thus important to design novel therapeutic strategies. The strategies based on TDP43 biology should be directed mainly to prevent ubiquitination and phosphorylation, to enhance protein aggregates clearance and block TDP-43 cytosolic mislocalization, as they are the most likely causative mechanisms of ALS/FTLD pathogenesis. ${ }^{52}$

\section{Modulation of TDP-43 proteostasis by small molecules}

As it has been mentioned, TDP-43 has emerged as a valuable therapeutic target for the discovery of effective treatments of several neurological severe and unmet diseases. ${ }^{67}$ Thus, modulation of its post-translational modifications by small molecules offers a great opportunity in the discovery of efficient drug candidates for the future treatment of ALS or FLTD, especially the ones directed towards homeostasis recovery. With the aim to provide new ideas for further drug discovery, some modulators of TDP43 are collected in the following section, mainly grouped by their mechanism of action.

\subsection{Protein kinase inhibitors}

One of the principal TDP-43 post-translational modifications that influences in its aggregation is phosphorylation. ${ }^{68}$ The phosphorylation of TDP-43 by kinases occurs at different residues present in the C-terminal domain of the protein, being the epitope S409/410 crucial for the abnormal oligomerization and fibril formation in vivo. Different protein kinases have been identified to phosphorylate TDP-43 so far: CK-1, CDC-7 and TTBK1/2. ${ }^{45-47}$

CK-1 was the first kinase identified to directly phosphorylate TDP- $43 .{ }^{45}$ The $C K-1$ gene codifies for seven different isoforms, but only isoforms $\delta$ and $\varepsilon$ are associated with TDP-43 phosphorylation. ${ }^{69,} 70$ Although several CK- $1 \delta$ selective and dual $\delta / \varepsilon$ selective inhibitors have been described, ${ }^{71}$ only the modulation of TDP-43 phosphorylation has been extensively studied for the benzothiazole family ${ }^{72}$ (Figure 3A). In 2014 Salado et al., described a new family of CK-1ठ inhibitors, being the $N$-Benzothiazolyl-2-phenylacetamides the most potent ones with $\mathrm{IC}_{50}$ values in the nano molar range. These inhibitors are ATP-competitive and show an excellent kinase selectivity profile against a wide panel of 456 kinases. ${ }^{72}$ These molecules were tested in a cellular assay showing their ability to decrease the ethacrynic acid (EA)- induced rise in p-TDP-43 levels. Cell treatment with EA causes a depletion of glutathione and consequent TDP. 
43 hyperphoshprylation. ${ }^{4}$ Finally, these small heterocyclic compounds were tested in a Drosophila Melanogaster transgenic model that expressed human TDP-43 and reproduced some of the human proteinopathy features such as neuron degeneration, cognitive impairment, reduced life span and abnormal hTDP-43 phosphorylation. Four inhibitors were tested and the lifespan of the animals was analyzed. All the active compounds were able to avoid the neurotoxic effect of the hTDP-43 expression and extend the lifespan of the flies, directly correlating with their $I_{50}$ values. The protective effects of CK-1ס inhibitors in TDP-43 proteinopathies suggest a potential therapeutic role for modulating TDP-43 hyperphosphorylation.

More recently, some of these compounds were further investigated in human cellular models of FTLD and ALS. These cells recapitulate some TDP-43 features present in human pathologies and represent an innovative, human-derived platform for drug discovery. ${ }^{73,74}$ CK-1 inhibitors, named IGS2.7 and IGS3.27 (Figure 3A), were tested in lymphoblasts of patients with FTLD-TDP and sporadic ALS showing significant results in the reduction of TDP-43 phosphorylation. Moreover, they were able to restore TDP43 homeostasis by recovering nuclear protein localization. Finally, an in vivo pharmacokinetic study of IGS2.7 proved that the compound is brain penetrant and orally bioavailable. These results suggest that inhibition of TDP-43 phosphorylation may be a promising therapy for ALS and FTLD and that CK-1 inhibitors can be considered promising candidates for their effective pharmacotherapy.

In 2016, Joshi et al..$^{75}$ described two new CK-1ठ inhibitors based on the benzothiazole derivatives described previously. These compounds, named as $\mathrm{CHC}$ and $\mathrm{DHC}$ (Figure $3 A$ ), were designed trough a novel QSAR computational model from a combinatorial library and their predicted activity pIC50 is 7.8, but their synthesis or experimental activity against the kinase has not been reported.

In 2018, a family of 28 new 1-(benzo[d]thiazol-2-yl)-3-phenylureas as CK1 inhibitors was described (Figure $3 \mathrm{~A}$ ). The inhibitory activity of the compounds was tested for CK1 $1 \delta$ and CK1 1 . Two of these ureas showed selective micro molar inhibition CK1 $\delta$ as well as the ability to cross the blood brain barrier. Further assays need to be performed in order to test the role these new compounds in the modulation of TDP-43 hyperphosphorylation ${ }^{76}$.

Cell division cycle kinase 7 (CDC7) is a Ser/Thr kinase involved in the control of DNA replication and cell cycle progression, which has been associated with cancer. Liachko et al. identified the $C$. elegans homolog for this kinase as responsible for the phosphorylation of TDP-43 in vivo. ${ }^{46}$ The authors described that the previously known ATP-competitive CDC7 inhibitor known as PHA767491 (Figure 3B), could revert the 
effects of TDP-43 hyperphosphorylation. The compound was tested in several cellular models and in C. elegans, showing toxic effects at concentrations higher than $90 \mu \mathrm{M}$, most likely due to the role of CDC-7 in cell cycle progresion. At $70 \mu \mathrm{M}$ the authors observed significant lower levels of TDP-43 phosphorylation. In addition, this inhibitor was able to reduce the loss of GABAergic motor neurons without interfering with the animal's growth. However, PHA767491 is not able to cross the human blood brain barrier ${ }^{77}$ and thus cannot be therapeutically applied to TDP-43 proteinopathies.

TTBK1 and TTBK2 are Ser/Thr and Tyr kinases that belong to the family of CK-1. Liachko et al. described the role of TTBK1 and TTBK2 in TDP-43 phosphorylation and neurodegeneration. ${ }^{47,78}$ TTBK1 is only expressed in the central nervous system, in adult brain cortex, cerebellum and the fetal brain. On the contrary, TTBK2 expression is ubiquitous and the enzyme is implicated in multiple crucial roles within the cell such as: microtubule stabilization, ciliogenesis and neurotransmitter transport. This difference remarks the advantage of selective inhibition of TTBK1 as a promising tool for the reduction of TDP-43 hyperphosphorylation, although to date no selective inhibitors have been reported..$^{79}$ There are only three TTBK $1 / 2$ inhibitors described in the literature (Figure 3C). ${ }^{80,81}$ These compounds show moderate inhibitory activity but their molecular role against TDP-43 phosphorylation or aggregation has not been investigated.

Finally, tyrosine kinase inhibitors nilotinib and bosutinib display a different mechanism of action than previous inhibitors. Nilotinib is a multitarget compound being its preferential targets $\mathrm{Bcr}-\mathrm{Abl}$ with $\mathrm{IC}_{50}$ below $30 \mathrm{nM}$ in murine myeloid progenitor cells. Bosutinib is a dual Scr/Abl inhibitor that presents $\mathrm{IC}_{50}$ of $1.2 \mathrm{nM}$ and $1 \mathrm{nM}$ respectively. The authors tested these two compounds in homozygous mice expressing human TDP-43. This model does not present muscular waste and paralysis, but the animals show a more FTLD-TDP phenotype characterized by anxiety, motor and cognitive defects. This over-expression triggers an increase in glutamate and $\mathrm{Y}$-amino butiric acid (GABA) and a reduced level of both glutamine and aspartate. These changes cause oxidative stress and disturbed synaptic function. Both nilotinib and bosutinib are able to reverse these toxic effects to the levels in control animals, ${ }^{82}$ together with a reduction in the nuclear and total levels of the protein. These data suggest the potential of tyrosine protein kinases inhibitors in recovering TDP-43 homeostasis. ${ }^{83}$

Here, Figure 3. 


\section{$\underline{\text { Inhibitors of stress granules }}$}

Boyd el al. published a high-content screening assay searching for inhibitors of TDP-43 inclusion formation. ${ }^{84}$ It has been reported that most TDP-43 inclusions co-localize with stress granules (SGs). TDP-43 associates with SG by interacting with SG proteins, either via direct protein-protein interactions, or as RNA. ${ }^{55}$ Compounds able to reduce SG formation have been shown to inhibit the formation of TDP-43 inclusions. The authors created a cellular model that increased oxidative stress by addition of sodium arsenite to a PC-12 cell line. In this study they tested 75000 molecules from a library and identified 16 interesting compounds with different scaffolds that did reduce the TDP-43 inclusions without any toxic effect. The selected compounds were tested in a C. elegans model expressing wt TDP-43 and mutated A315T TDP-43. Heterocyclic compound LND-0130436 (Figure 4) was able to protect against the neuronal loss mediated by TDP-43 accumulation and improved some behavioral defects. Further studies are needed to identify the exact mechanism of the compound.

The role of cyclin dependent kinases (CDK) and GSK3 inhibitors in TDP-43 stress granule formation has also been studied. ${ }^{48}$ GSK-3 inhibitors SB216736 and SB415286, as well as $C D K$ inhibitors arcyriaflavin $A$, olomoucine and ryuvidine showed a reduction on TDP-43-positive stress granule formation, although additional research is needed in order to clarify the exact mechanisms of these two kinases in the TDP-43 proteinopathy.

\section{Here, Figure 4.}

\section{Autophagy modulators}

Autophagy degradation pathway has become a potential therapeutic target in neurodegenerative diseases with proteins inclusions, including TDP-43 proteinopathies. Cytosolic TDP-43 is degraded by both, the ubiquitin-proteasome system and the autophagy lysosomal pathway, either as a full-length protein or Cterminal fragments. ${ }^{44}$ It has been reported that in aging, in ALS and FTLD animal models and in other neurodegenerative diseases, a progressive decrease in the efficiency of these protein degradation systems occurs. ${ }^{86}$ Indeed, TDP-43 is implicated in autophagy regulation as previously described in section 2.2. TDP-43 stabilizes the mRNA of autophagy-related genes like ATG7. ${ }^{55}$ Failures in these clearance systems provoke the accumulation of TDP-43 in form of cytotoxic protein aggregates that could establish the onset of the disease. ${ }^{44}$ 
All this data together supports the induction of autophagy as a potential therapeutic strategy for accelerating the removal of cytotoxic aggregates. Thus, identification of molecules targeting the modulation of TDP-43 degradation pathway might be effective drugs for TDP-43 proteinopathies. ${ }^{44}$

Rapamycin has been proved to be an inductor of autophagy (Figure 5). Rapamycin was first discovered as an antifungal metabolite isolated from Streptomyces hygroscopius. ${ }^{87}$ It has been used as a therapeutic drug for cancer due to its antiproliferative properties and as an immunosuppressant for organ transplantation. ${ }^{88}$ Rapamycin is an inhibitor of the mammalian target of rapamycin (mTOR). mTOR negatively regulates autophagy, therefore its inhibition would lead to an increase in the autophagic flux. Inhibition of mTOR by rapamycin reduces the $25-\mathrm{kDa}$ C-terminal TDP43 fragment accumulation and restores protein localization in N2a and SH-SY5Y cells that overexpressed the C-terminal fragment. ${ }^{89}$

Recent studies have revealed that rapamycin could also be used as a therapeutic drug for neurodegenerative diseases, due to its neuroprotective effect in several neurodegenerative disease models, including diseases with TDP-43 proteinopathies. ${ }^{90}$ Rapamycin recovered the learning/memory capability and ameliorated motor neuron function in FTLD mice carrying a TDP-43 transgene. ${ }^{90}$ In ALS-TDP Drosophila with overexpressed dTDP (Drosophila ortholog of TDP-43), rapamycin could partially improve the shortened lifespan and impaired locomotor activity of the flies. ${ }^{91}$ However, failures of rapamycin as a therapeutic drug have also been reported. Some studies revealed that rapamycin could not only rescue the phenotype of SOD1G93A ALS mice but also exacerbated the symptoms. ${ }^{92}$ In this sense, alternative activators of the autophagy pathway with fewer side effects are needed.

Other potent autophagy activator is the traditional herb medicine, berberine that targets the AMPK/mTOR/ULK1 signaling. Berberine is an isoquinoline quaternary alkaloid highly used in traditional Chinese medicine in diverse diseases and as dietary nutritional supplement (Figure 5). ${ }^{93}$ Berberine is known to have several pharmacological properties such as antidiabetic, antimicrobial, antihyperlipidemic, antiinflammatory, antitumoral and antioxidant. ${ }^{94}$ Different studies have also proved its low side effects and cellular toxicity, its high tolerance for orally-taken doses and its blood brain barrier permeability, supporting berberine as an alternative drug for neurodegenerative diseases. ${ }^{95}$ Recently, it has been proved that berberine has a potent neuroprotective effect by reversing the process by which insoluble TDP-43 aggregates are formed. Berberine promoted the degradation rates of TDP-43 and 
decreased aggregate formation of truncated TDP-43 fragments through activating the autophagic function in N2a cells transfected with human TDP-43.96

Alternatively, autophagy can be induced by mTOR-independent signaling. Trehalose, a natural disaccharide non-synthesized by mammalian cells, induces autophagy by different pathways not involving mTOR. Trehalose is an activator of the transcriptional activator transcription factor EB (TFEB) (Figure 5). TFEB is a regulator of lysosome biogenesis, autophagosome formation and autophagosome-lysosome fusion increasing the autophagy degradative pathway. ${ }^{97}$ Trehalose treatment significantly reduced TDP-43 accumulation in an ALS cell model and in models of motor neuron degeneration by activation of TFEB which enhanced the autophagy and clearance of TDP-43.98 99 Furthermore, trehalose can also promote autophagy mTOR-independent mediated by progranulin (PGRN). ${ }^{100}$ PGRN is a secreted growth factor important for neuronal survival, modulation of inflammation and regulation of lysosome homeostasis. One of the most common causes of FTLD is the mutation in the GRN gene, that has also been reported in other neurodegenerative diseases. ${ }^{101}$ To the best of our knowledge, only two small molecules that increase PGRN have been published, that belong to the families of alkalizing agents and inhibitors of the autophagy flux, and selective histone deacetylase inhibitors, such as vorinostat. Vorinostat increases PGRN transcription and also induces autophagy, but its molecular target and mechanism is not clear and it may result toxic in long-term administration. ${ }^{102}$ Recently, it has been proved that trehalose increases the PGRN levels in human fibroblasts and in neurons derived from induced pluripotent stem cells (iPSCs) generated from GRN mutation carriers. Considering all the above, trehalose treatment could be a promising therapeutic strategy for neurodegenerative diseases by boosting the autophagy flux. ${ }^{100}$

Here, Figure 5.

According to all the results summarized here, the modulation of autophagy is a very promising therapeutic strategy for TDP-43 proteinopathies as well as for other neurodegenerative diseases with protein inclusions.

\subsection{Other TDP-43 modulators}

To avoid the pathological nuclear exclusion and cytoplasmic deposition of TDP-43, nuclear export inhibitors have been used. ${ }^{103}$ These compounds target the nuclear receptor exportin-1 (XPO1) and are known as KPT-335 and KPT-350 (Figure 6). Both XPO1 inhibitors modestly extend cellular survival in neuronal ALS/FTLD models and mitigate motor symptoms in an in vivo rat ALS model. Furthermore, they are not able to 
enhance nuclear TDP-43 levels, while depletion of XPO1 or other exportins had little effect on TDP-43 localization. ${ }^{104}$ These data suggest that therapeutic prevention of cytoplasmic TDP-43 accumulation in ALS/FTLD may be enhanced by targeting several overlapping mechanisms. It is worth mentioning that when blocking the phosphorylation of TDP-43 by CK1 inhibitors, not only this post translational modification is avoided but also the nuclear content of TDP-43 was increased reducing the cytoplasmic localization in human lymphoblasts of FTLD patients. ${ }^{73}$ Anyhow, Biogen has recently acquired KPT-350 for further development into clinical trials based on its potential as ALS therapy.

Finally, in an effort to discover new small molecules to modulate TDP-43 pathology a phenotypic screening of 1200 FDA approved molecules was performed in an ALS model of Drosophila. Pioglitazone, a PPARy activator, was neuroprotective in TDP-43 transgenic flies and also showed a restoration in metabolites alteration and locomotor deficits in motor neurons. ${ }^{105}$ However this activator was not able to reduce locomotor deficits in muscle, and produced no beneficial effects on animal lifespan on this or other animal models based on FUS or SOD mutations. These results are consistent with clinical trial outcomes of pioglitazone in ALS patients ${ }^{106}$ and therefore more research is needed to understand the role of PPARY activation in TDP-43 modulation.

Here, Figure 6.

\section{Cellular and animal models to evaluate TDP-43 homeostasis}

In vitro technologies to model neurological disorders are essential to unravel the molecular pathology of and to investigate new therapeutic strategies. ${ }^{107}$

Different murine and human cell lines such as PC12, SH-SY5Y, HEK293 and Neuro2a (N2a) are commonly used to model neuronal cells. Considering that ALS specifically affects motor neurons, the NSC-34 cell line is also employed. This cell line expresses several motor neuron characteristics and derives from the fusion of neuroblastoma cells with spinal cord cells. ${ }^{108}$

In order to model TDP-43 proteinopathies, cell lines are transfected to overexpress this protein. Transfection with human full-length (FL) TDP-43 or with the $25 \mathrm{kDa}$ C-terminal fragment results in TDP-43 aggregation in the cytosol. ${ }^{96,} 98$ TDP-43 aggregates can also be pre-formed in transformed bacteria overexpressing FL and C-term TDP-43. The resulting inclusion bodies mainly composed by TDP-43 and C-terminal TDP-43 fragments are injected in the cell lines. It has been proved that these aggregates recruit 
nuclear TDP-43 in the cytosol causing nuclear depletion, mimicking TDP-43 pathogenesis. ${ }^{44}$

Ethacrynic acid (EA) treatment reproduces pathological modification of TDP-43 linked to TDP-43 proteinopathies. ${ }^{4}$ EA provokes glutathione depletion, increasing and inducing TDP-43 C-terminal phosphorylation at Ser403/404 and 409/410 with the final formation of TDP-43 aggregates in the cytosol. Therefore, it is used in cell lines to mimic the pathological process of TDP-43 proteinopathies. ${ }^{4}$

Primary cultures like mouse spinal cord cultures and motor neurons are also used for studying TDP-43 homeostasis. ${ }^{107,} 109$ These primary cultures can also be obtained from transgenic animals with mutations in genes related to ALS. Other in vitro models such as organotypic rat spinal cord slice and post-mortem samples of brain and spinal cord from ALS patients are frequently used. The examination of post-mortem tissue is the most accurate model available currently that confirms disease. This model has led to a great understanding of disease pathology and to the discovery of molecular targets that may be involved in ALS, but it offers and end-stage phase of the pathology masking disease origin. ${ }^{107}$ Additionally, immortalized lymphocytes from sporadic ALS or FTLD patients show an increase in TDP-43 phosphorylation and truncation as well as alteration of TDP-43 homeostasis. Therefore, lymphoblasts represent a useful model to study the pathological mechanisms of ALS and a platform to select potential therapeutic candidates due to their common features involved in the ALS and the cell accessibility. ${ }^{74}$

The use of induced pluripotent stem cells (iPSCs) have opened the possibility of developing human in vitro models of neurodegenerative diseases and they have enabled for the first time the in vitro use of human neurons without utilizing embryonic cells. ${ }^{110}$ Since Dimos et al. cultured the first human iPSC-derived motor neuron in a petri dish in 2008, ${ }^{111}$ different protocols have been developed and optimized to produce iPSC lines through genetic reprogramming. Human fibroblasts from patients are reprogrammed to iPSCs by using selected transcription factors and are then differentiated under the appropriate conditions to become motor neuron cells. ${ }^{107}$ This technology offers a very promising opportunity to finally develop in vitro models for ALS and FTLD carrying a specific mutation. ${ }^{112}$ iPSCs also present a chance to model not only the familiar cases of ALS, but also sporadic types of disease which are the major amount of ALS patients. Different studies have already used this in vitro model to understand the molecular pathology and for screening potential pharmacological agents. ${ }^{113}$ However, this revolutionary technology has recently emerged and there is 
still more investigation needed to establish iPSCs as standard models for understanding the disease and as a platform for selecting therapeutic agents.

From the discovery of TDP-43 mutations in sporadic ALS and FTLD patients ${ }^{13,114}$ there has been a great effort to develop a TDP-43 based animal model that could mimic these diseases and replace the SOD mouse model in ALS, which had been the main animal model used for preclinical trials, even though SOD mutations account only for $20 \%$ of patients with familial ALS (10\%). However, and similarly to other neurodegenerative diseases, it remains a challenge to find accurate animal models of ALS or FTLD.

A wide variety of animal models of TDP-43 proteinopathy have been developed in Drosophila, C. Elegans, Zebrafish, mice and rats, using native or mutant TDP-43, that use different promoters or inducing systems. ${ }^{115}$ The different findings from these animal models seem to suggest that TDP-43 mediated neurodegeneration is caused by the loss of function of this protein rather than by the potential toxicity of the cytoplasmic aggregates, although this controversial fact is not fully understood. ${ }^{116}$ The ability of these TDP-43 models to mimic human disease has been a complicated task, encountering multiple challenges such as promoter-dependent effects, tolerability of mutant gene expression and overexpression phenotypic artifacts ${ }^{117}$ not related to human diseases. ${ }^{118}$ The first rodent models overexpressing wildtype or mutated TDP. 43 showed early onset neurological phenotypes associated with varied molecular pathology in the first weeks of life. ${ }^{119,120}$ The high variability of pathological features encountered manifest the requirement of a high regulated homeostasis of TDP-43 for a normal brain function, together with the elusive nature and limited insights gained on TDP-43 mediated pathways. Protein aggregates found in the brain of these rodents could be found differently located: only in the cytoplasm for some models ${ }^{121}$ and both in nuclei and cytoplasm for others. ${ }^{122}$ Also the composition of the aggregates was heterogeneous, finding in some cases that TDP-43 was not the most abundant protein. ${ }^{122}$ It is worth mentioning that when the first Prnp-A315T mice ${ }^{120}$ were developed and studied by different groups using congenic instead of mixed genetic backgrounds, these mice exhibited progressive neurodegeneration in the colon that led to gastrointestinal obstruction and sudden death. This phenotypic artifact masked neurodegeneration in these mice, however a posterior study showed that when feeding the animals a high fat gel based diet extended their lifespan showing progressive ALS phenotype. ${ }^{123}$ Subsequent mouse models were developed with more restricted promoters to isolate TDP-43 effects in the brain; however the results have also been 
highly heterogeneous. ${ }^{36,122,124}$ Very recently a new TDP-43 mouse model has been described with a human-equivalent mutation in the endogenous mouse TARDBP gene ${ }^{125}$ that reduces the phenotypic artefacts caused by TDP-43 overexpression. This study emphasizes a central role for TDP-43 in neurodegeneration, but did not recapitulate clinical symptoms of human ALS like motor impairment, suggesting it could be a model for FTLD. Despite the challenges facing the development of a suitable TDP-43 animal model the different attempts have enabled the discovery of some insights of TDP-43 proteinopathy and the possibility to find potential pharmacological targets. ${ }^{126}$ For example, it has been recently observed that redundant pathways may regulate TDP-43 nuclear export, suggesting the absence of a single transporter for TDP-43 nuclear export. ${ }^{104}$ Nucleo-cytoplasmic transport mediated by TDP-43 has also been recently indicated as a possible common molecular pathway in ALS and FTLD. ${ }^{127}$ Interestingly, a mouse model generated with a doxycycline (Dox)suppressible expression of human TDP-43 that showed progressive motor neuron degeneration leading to death exhibited a rescue of motor impairments, and an extension of lifespan and muscle reinnervation through suppression of TDP-43 expression after disease onset, which highlights the CNS ability to repair itself even at developed stages of ALS or FTLD. ${ }^{128}$ Another recent and very interesting research work suggested the spread of TDP-43 pathology in vivo for the first time. ${ }^{129}$

Altogether, further research is still needed to generate improved animal models in order to understand TDP-43 implication in disease and be used as tools to discover new drugs. The pathological features encountered in humans still differ greatly from the ones encountered in these transgenic models and still a real translation from animal model to patients has yet to be observed. ${ }^{130}$

\section{Conclusions}

The nuclear protein TDP-43 plays a key role in the molecular pathology of several neurodegenerative diseases, and is emerging as a relevant target for many proteinopathies, especially ALS and FLTD. Although great research advances in last years have provided valuable information about the physiological and pathological role of TDP-43 in the human being, there are many functions that remain to be discovered. Anyhow, some small molecules have been assayed as modulators of TDP-43 homeostasis (Figure 7). Some of them are able to decrease TDP-43 aggregates only, such as stress granules or autophagy modulators. Others are responsible of decreasing protein hyperphosphorylation in the cytoplasm. When the dynamic 
equilibrium between nucleus and cytoplasm that governs functional levels of nuclear TDP-43 is altered in the pathological states, post-translational modifications appear in the cytoplasm that is the cellular activity location. It is very interesting that reducing cytoplasmic phosphorylation on TDP-43 reverts this equilibrium and promotes the homeostasis recovery. The fact that this behavior is found not only in different cell cultures but also in lymphoblasts from ALS and FLTD patients points to a relevant mechanism for further therapeutic intervention.

\section{Here, Figure 7.}

Development of new cellular and animal models, including the use of neurons or motor neurons derived from iPSCs, provide the basis for searching compounds able to interfere with imbalanced TDP-43 homeostasis, thus improving the drug discovery process. Studies targeted to foster the race in exploring these new emergent targets may be very relevant for the discovery of an effective drug for the severe FLTD or the fatal ALS. Meanwhile, valuable chemical tools for the study of the roles of TDP-43 in physiology and pathology have been developed. Appropriate optimization of their selectivity and drug-like properties such as brain permeability may generate valuable drug candidates. However, in the end, only clinical trials will be able to provide the urgent answer that patients wait.

\section{Acknowledgements}

Funding from Comunidad de Madrid (B2017/BMD3813 ELA-Madrid), MINECO (SAF2016-76693-R), ISCiii (CIBERNED, CB18/05/00040) and La Caixa Junior Leader retaining program is acknowledged. V.N. holds a pre-doctoral FPU grant (FPU16/04466). S.N. was supported by an stipend from the Bio4Med Program (MarieSklodowska-Curie Cofound gran agreement 665735).

\section{Competing interests}

The authors declare that they have no competing interests.

\section{Author's contribution:}

A.M. and A.M-R. have equal seniority. V.P. A.M., and A.M-R. conceived and designed this study. V.N, A.M, and A.M-R designed the figures. All authors performed the literature research, and the manuscript was written through contribution of all authors, who have given approval to the final version. 


\section{References}

1. Jellinger, K. A. Basic mechanisms of neurodegeneration: a critical update. J. Cell. Mol. Med. 2010, 14, 457-87.

2. Ingelsson, M.; Hyman, B. T. Disordered proteins in dementia. Ann. Med. 2002, 34, 259-71.

3. Citron, M.; Westaway, D.; Xia, W.; Carlson, G.; Diehl, T.; Levesque, G.; Johnson-Wood, K.; Lee, M.; Seubert, P.; Davis, A.; Kholodenko, D.; Motter, R.; Sherrington, R.; Perry, B.; Yao, H.; Strome, R.; Lieberburg, I.; Rommens, J.; Kim, S.; Schenk, D.; Fraser, P.; St George Hyslop, P.; Selkoe, D. J. Mutant presenilins of Alzheimer's disease increase production of 42-residue amyloid beta-protein in both transfected cells and transgenic mice. Nat. Med. 1997, 3, 67-72.

4. Iguchi, Y.; Katsuno, M.; Takagi, S.; Ishigaki, S.; Niwa, J.; Hasegawa, M.; Tanaka, F.; Sobue, G. Oxidative stress induced by glutathione depletion reproduces pathological modifications of TDP-43 linked to TDP-43 proteinopathies. Neurobiol. Dis. 2012, 45, 862-70.

5. Correia, A. S.; Patel, P.; Dutta, K.; Julien, J. P. Inflammation Induces TDP-43 Mislocalization and Aggregation. PLoS One 2015, 10, e0140248.

6. Herva, M. E.; Spillantini, M. G. Parkinson's disease as a member of Prion-like disorders. Virus Res. 2015, 207, 38-46.

7. Sambataro, F.; Pennuto, M. Post-translational modifications and protein quality control in motor neuron and polyglutamine diseases. Front. Mol. Neurosci. 2017, 10, 82.

8. Sipe, J. D.; Cohen, A. S. Review: history of the amyloid fibril. J. Struct. Biol. 2000, 130, 88-98.

9. Williams, D. R. Tauopathies: classification and clinical update on neurodegenerative diseases associated with microtubule-associated protein tau. Intern. Med. J. 2006, 36, 652-60.

10. Spillantini, M. G.; Goedert, M. The alpha-synucleinopathies: Parkinson's disease, dementia with Lewy bodies, and multiple system atrophy. Ann. N. Y. Acad. Sci. 2000, 920, 16-27.

11. Shelkovnikova, T. A. Modelling FUSopathies: focus on protein aggregation. Biochem. Soc. Trans. 2013, 41, 1613-7.

12. Huang, S.; Zhu, S.; Li, X. J.; Li, S. The Expanding Clinical Universe of Polyglutamine Disease. Neuroscientist 2019.

13. Neumann, M.; Sampathu, D. M.; Kwong, L. K.; Truax, A. C.; Micsenyi, M. C.; Chou, T. T.; Bruce, J.; Schuck, T.; Grossman, M.; Clark, C. M.; McCluskey, L. F.; Miller, B. L.; Masliah, E.; Mackenzie, I. R.; Feldman, H.; Feiden, W.; Kretzschmar, H. A.; Trojanowski, J. Q.; Lee, V. M. Ubiquitinated TDP-43 in frontotemporal lobar degeneration and amyotrophic lateral sclerosis. Science 2006, 314, 130-3.

14. Heyburn, L.; Moussa, C. E. TDP-43 in the spectrum of MND-FTLD pathologies. Mol. Cell. Neurosci. 2017, 83, 46-54.

15. Josephs, K. A.; Murray, M. E.; Whitwell, J. L.; Tosakulwong, N.; Weigand, S. D.; Petrucelli, L.; Liesinger, A. M.; Petersen, R. C.; Parisi, J. E.; Dickson, D. W. Updated TDP-43 in Alzheimer's disease staging scheme. Acta Neuropathol. 2016, 131, 571-85. 
16. Chanson, J. B.; Echaniz-Laguna, A.; Vogel, T.; Mohr, M.; Benoilid, A.; Kaltenbach, G.; Kiesmann, M. TDP43-positive intraneuronal inclusions in a patient with motor neuron disease and Parkinson's disease. Neurodegener. Dis. 2010, 7, 260-4.

17. Schwab, C.; Arai, T.; Hasegawa, M.; Yu, S.; McGeer, P. L. Colocalization of transactivation-responsive DNA-binding protein 43 and huntingtin in inclusions of Huntington disease. J. Neuropathol. Exp. Neurol. 2008, 67, 1159-65.

18. Davis, S. A.; Gan, K. A.; Dowell, J. A.; Cairns, N. J.; Gitcho, M. A. TDP-43 expression influences amyloidbeta plaque deposition and tau aggregation. Neurobiol. Dis. 2017, 103, 154-162.

19. Turner, B. J.; Baumer, D.; Parkinson, N. J.; Scaber, J.; Ansorge, O.; Talbot, K. TDP-43 expression in mouse models of amyotrophic lateral sclerosis and spinal muscular atrophy. BMC Neurosci. 2008, 9, 104.

20. Reddi, P. P. Transcription and splicing factor TDP-43: role in regulation of gene expression in testis. Semin. Reprod. Med. 2017, 35, 167-172.

21. Ou, S. H.; Wu, F.; Harrich, D.; Garcia-Martinez, L. F.; Gaynor, R. B. Cloning and characterization of a novel cellular protein, TDP-43, that binds to human immunodeficiency virus type 1 TAR DNA sequence motifs. J. Virol. 1995, 69, 3584-96.

22. Winton, M. J.; Igaz, L. M.; Wong, M. M.; Kwong, L. K.; Trojanowski, J. Q.; Lee, V. M. Disturbance of nuclear and cytoplasmic TAR DNA-binding protein (TDP-43) induces disease-like redistribution, sequestration, and aggregate formation. J. Biol. Chem. 2008, 283, 13302-9.

23. Hebron, M. L.; Lonskaya, I.; Sharpe, K.; Weerasinghe, P. P.; Algarzae, N. K.; Shekoyan, A. R.; Moussa, C. E. Parkin ubiquitinates Tar-DNA binding protein-43 (TDP43) and promotes its cytosolic accumulation via interaction with histone deacetylase 6 (HDAC6). J. Biol. Chem. 2013, 288, 4103-15.

24. Ratti, A.; Buratti, E. Physiological functions and pathobiology of TDP-43 and FUS/TLS proteins. J. Neurochem. 2016, 138 Suppl 1, 95-111.

25. Ling, J. P.; Pletnikova, O.; Troncoso, J. C.; Wong, P. C. TDP-43 repression of nonconserved cryptic exons is compromised in ALS-FTD. Science 2015, 349, 650-5.

26. Jeong, Y. H.; Ling, J. P.; Lin, S. Z.; Donde, A. N.; Braunstein, K. E.; Majounie, E.; Traynor, B. J.; LaClair, K. D.; Lloyd, T. E.; Wong, P. C. Tdp-43 cryptic exons are highly variable between cell types. Mol. Neurodegener. 2017, 12, 13.

27. Kawahara, Y.; Mieda-Sato, A. TDP-43 promotes microRNA biogenesis as a component of the Drosha and Dicer complexes. Proc. Natl. Acad. Sci. U. S. A. 2012, 109, 3347-52.

28. Bartel, D. P. Metazoan MicroRNAs. Cell 2018, 173, 20-51.

29. Jawaid, A.; Woldemichael, B. T.; Kremer, E. A.; Laferriere, F.; Gaur, N.; Afroz, T.; Polymenidou, M.; Mansuy, I. M. Memory decline and its reversal in aging and neurodegeneration involve mir-183/96/182 biogenesis. Mol. Neurobiol. 2018.

30. Kim, K. Y.; Lee, H. W.; Shim, Y. M.; Mook-Jung, I.; Jeon, G. S.; Sung, J. J. A phosphomimetic mutant TDP-43 (S409/410E) induces Drosha instability and cytotoxicity in Neuro 2A cells. Biochem. Biophys. Res. Commun. 2015, 464, 236-43.

31. Ayala, Y. M.; De Conti, L.; Avendano-Vazquez, S. E.; Dhir, A.; Romano, M.; D'Ambrogio, A.; Tollervey, J.; Ule, J.; Baralle, M.; Buratti, E.; Baralle, F. E. TDP-43 regulates its mRNA levels through a negative feedback loop. EMBO J. 2011, 30, 27788.

32. Hawley, Z. C. E.; Campos-Melo, D.; Strong, M. J. Novel miR-b2122 regulates several ALS-related RNA-binding proteins. Mol. Brain 2017, 10, 46. 
33. Ling, S. C.; Albuquerque, C. P.; Han, J. S.; Lagier-Tourenne, C.; Tokunaga, S.; Zhou, H.; Cleveland, D. W. ALS-associated mutations in TDP-43 increase its stability and promote TDP-43 complexes with FUS/TLS. Proc. Natl. Acad. Sci. U. S. A. 2010, 107, 13318-23.

34. Ash, P. E.; Zhang, Y. J.; Roberts, C. M.; Saldi, T.; Hutter, H.; Buratti, E.; Petrucelli, L.; Link, C. D. Neurotoxic effects of TDP-43 overexpression in C. elegans. Hum. Mol. Genet. 2010, 19, 3206-18.

35. Li, Y.; Ray, P.; Rao, E. J.; Shi, C.; Guo, W.; Chen, X.; Woodruff, E. A., 3rd; Fushimi, K.; Wu, J. Y. A Drosophila model for TDP-43 proteinopathy. Proc. Natl. Acad. Sci. U. S. A. 2010, 107, 3169-74.

36. Tsai, K. J.; Yang, C. H.; Fang, Y. H.; Cho, K. H.; Chien, W. L.; Wang, W. T.; Wu, T. W.; Lin, C. P.; Fu, W. M.; Shen, C. K. Elevated expression of TDP-43 in the forebrain of mice is sufficient to cause neurological and pathological phenotypes mimicking FTLD-U. J. Exp. Med. 2010, 207, 1661-73.

37. Barmada, S. J.; Ju, S.; Arjun, A.; Batarse, A.; Archbold, H. C.; Peisach, D.; Li, X.; Zhang, Y.; Tank, E. M.; Quu, H.; Huang, E. J.; Ringe, D.; Petsko, G. A.; Finkbeiner, S. Amelioration of toxicity in neuronal models of amyotrophic lateral sclerosis by hUPF1. Proc. Natl. Acad. Sci. U. S. A. 2015, 112, 7821-6.

38. Alquezar, C.; Esteras, N.; Alzualde, A.; Moreno, F.; Ayuso, M. S.; Lopez de Munain, A.; Martin-Requero, A. Inactivation of $\mathrm{CDK} / \mathrm{pRb}$ pathway normalizes survival pattern of lymphoblasts expressing the FTLD-progranulin mutation c.709-1G>A. PLoS One 2012, 7, e37057.

39. Polymenidou, M.; Lagier-Tourenne, C.; Hutt, K. R.; Huelga, S. C.; Moran, J.; Liang, T. Y.; Ling, S. C.; Sun, E.; Wancewicz, E.; Mazur, C.; Kordasiewicz, H.; Sedaghat, Y.; Donohue, J. P.; Shiue, L.; Bennett, C. F.; Yeo, G. W.; Cleveland, D. W. Long pre-mRNA depletion and RNA missplicing contribute to neuronal vulnerability from loss of TDP-43. Nat. Neurosci. 2011, 14, 459-68.

40. Ayala, Y. M.; Zago, P.; D'Ambrogio, A.; Xu, Y. F.; Petrucelli, L.; Buratti, E.; Baralle, F. E. Structural determinants of the cellular localization and shuttling of TDP43. J. Cell Sci. 2008, 121, 3778-85.

41. Cohen, T. J.; Hwang, A. W.; Restrepo, C. R.; Yuan, C. X.; Trojanowski, J. Q.; Lee, V. M. An acetylation switch controls TDP-43 function and aggregation propensity. Nat. commun. 2015, 6, 5845.

42. Neumann, M.; Kwong, L. K.; Lee, E. B.; Kremmer, E.; Flatley, A.; Xu, Y.; Forman, M. S.; Troost, D.; Kretzschmar, H. A.; Trojanowski, J. Q.; Lee, V. M. Phosphorylation of S409/410 of TDP-43 is a consistent feature in all sporadic and familial forms of TDP-43 proteinopathies. Acta Neuropathol. 2009, 117, 137-49.

43. Zhang, Y. J.; Gendron, T. F.; Xu, Y. F.; Ko, L. W.; Yen, S. H.; Petrucelli, L. Phosphorylation regulates proteasomal-mediated degradation and solubility of TAR DNA binding protein-43 C-terminal fragments. Mol. Neurodegener. 2010, 5, 33.

44. Cascella, R.; Fani, G.; Capitini, C.; Rusmini, P.; Poletti, A.; Cecchi, C.; Chiti, F. Quantitative assessment of the degradation of aggregated TDP-43 mediated by the ubiquitin proteasome system and macroautophagy. FASEB J. 2017, 31, 5609-5624.

45. Kametani, F.; Nonaka, T.; Suzuki, T.; Arai, T.; Dohmae, N.; Akiyama, H.; Hasegawa, M. Identification of casein kinase-1 phosphorylation sites on TDP-43. Biochem. Biophys. Res. Commun. 2009, 382, 405-9. 
46. Liachko, N. F.; McMillan, P. J.; Guthrie, C. R.; Bird, T. D.; Leverenz, J. B.; Kraemer, B. C. CDC7 inhibition blocks pathological TDP-43 phosphorylation and neurodegeneration. Ann. Neurol. 2013, 74, 39-52.

47. Liachko, N. F.; McMillan, P. J.; Strovas, T. J.; Loomis, E.; Greenup, L.; Murrell, J. R.; Ghetti, B.; Raskind, M. A.; Montine, T. J.; Bird, T. D.; Leverenz, J. B.; Kraemer, B. C. The tau tubulin kinases TTBK1/2 promote accumulation of pathological TDP-43. PLoS Genet. 2014, 10, e1004803.

48. Moujalled, D.; James, J. L.; Parker, S. J.; Lidgerwood, G. E.; Duncan, C.; Meyerowitz, J.; Nonaka, T.; Hasegawa, M.; Kanninen, K. M.; Grubman, A.; Liddell, J. R.; Crouch, P. J.; White, A. R. Kinase inhibitor screening identifies cyclin-dependent kinases and glycogen synthase kinase 3 as potential modulators of TDP-43 cytosolic accumulation during cell stress. PLoS One 2013, 8, e67433.

49. Li, W.; Reeb, A. N.; Lin, B.; Subramanian, P.; Fey, E. E.; Knoverek, C. R.; French, R. L.; Bigio, E. H.; Ayala, Y. M. Heat shock-induced phosphorylation of tar DNA-binding protein 43 (TDP-43) by mapk/erk kinase regulates TDP-43 function. J. Biol. Chem. 2017, 292, 5089-5100.

50. Liachko, N. F.; Saxton, A. D.; McMillan, P. J.; Strovas, T. J.; Currey, H. N.; Taylor, L. M.; Wheeler, J. M.; Oblak, A. L.; Ghetti, B.; Montine, T. J.; Keene, C. D.; Raskind, M. A.; Bird, T. D.; Kraemer, B. C. The phosphatase calcineurin regulates pathological TDP-43 phosphorylation. Acta Neuropathol. 2016, 132, 545-61.

51. Lee, B. H.; Lee, M. J.; Park, S.; Oh, D. C.; Elsasser, S.; Chen, P. C.; Gartner, C.; Dimova, N.; Hanna, J.; Gygi, S. P.; Wilson, S. M.; King, R. W.; Finley, D. Enhancement of proteasome activity by a small-molecule inhibitor of USP14. Nature 2010, 467, 179-84.

52. Scotter, E. L.; Chen, H. J.; Shaw, C. E. TDP-43 proteinopathy and ALS: Insights into disease mechanisms and therapeutic targets. Neurotherapeutics 2015, 12, 352-63.

53. Johansen, T.; Lamark, T. Selective autophagy mediated by autophagic adapter proteins. Autophagy 2011, 7, 279-96.

54. Ravikumar, B.; Futter, M.; Jahreiss, L.; Korolchuk, V. I.; Lichtenberg, M.; Luo, S.; Massey, D. C.; Menzies, F. M.; Narayanan, U.; Renna, M.; JimenezSanchez, M.; Sarkar, S.; Underwood, B.; Winslow, A.; Rubinsztein, D. C. Mammalian macroautophagy at a glance. J. Cell Sci. 2009, 122, 1707-11.

55. Bose, J. K.; Huang, C. C.; Shen, C. K. Regulation of autophagy by neuropathological protein TDP-43. J. Biol. Chem. 2011, 286, 44441-8.

56. Xia, Q.; Wang, H.; Hao, Z.; Fu, C.; Hu, Q.; Gao, F.; Ren, H.; Chen, D.; Han, J.; Ying, Z.; Wang, G. TDP-43 loss of function increases TFEB activity and blocks autophagosome-lysosome fusion. EMBO J. 2016, 35, 121-42.

57. Filimonenko, M.; Stuffers, S.; Raiborg, C.; Yamamoto, A.; Malerod, L.; Fisher, E. M.; Isaacs, A.; Brech, A.; Stenmark, H.; Simonsen, A. Functional multivesicular bodies are required for autophagic clearance of protein aggregates associated with neurodegenerative disease. J. Cell Biol. 2007, 179, 485-500.

58. Kim, S. H.; Shi, Y.; Hanson, K. A.; Williams, L. M.; Sakasai, R.; Bowler, M. J.; Tibbetts, R. S. Potentiation of amyotrophic lateral sclerosis (ALS)-associated TDP43 aggregation by the proteasome-targeting factor, ubiquilin 1. J. Biol. Chem. 2009, 284, 8083-92.

59. Brady, O. A.; Meng, P.; Zheng, Y.; Mao, Y.; Hu, F. Regulation of TDP-43 aggregation by phosphorylation and p62/SQSTM1. J. Neurochem. 2011, 116, 248-59. 
60. Barmada, S. J.; Serio, A.; Arjun, A.; Bilican, B.; Daub, A.; Ando, D. M.; Tsvetkov, A.; Pleiss, M.; Li, X.; Peisach, D.; Shaw, C.; Chandran, S.; Finkbeiner, S. Autophagy induction enhances TDP43 turnover and survival in neuronal ALS models. Nat. Chem. Biol. 2014, 10, 677-85.

61. Khalil, B.; Lievens, J. C. Mitochondrial quality control in amyotrophic lateral sclerosis: towards a common pathway? Neural. Regen. Res. 2017, 12, 1052-1061.

62. Wang, W.; Wang, L.; Lu, J.; Siedlak, S. L.; Fujioka, H.; Liang, J.; Jiang, S.; Ma, X.; Jiang, Z.; da Rocha, E. L.; Sheng, M.; Choi, H.; Lerou, P. H.; Li, H.; Wang, $X$. The inhibition of TDP-43 mitochondrial localization blocks its neuronal toxicity. Nat. Med. 2016, 22, 869-78.

63. Russell, A. P.; Wada, S.; Vergani, L.; Hock, M. B.; Lamon, S.; Leger, B.; Ushida, T.; Cartoni, R.; Wadley, G. D.; Hespel, P.; Kralli, A.; Soraru, G.; Angelini, C.; Akimoto, T. Disruption of skeletal muscle mitochondrial network genes and miRNAs in amyotrophic lateral sclerosis. Neurobiol. Dis. 2013, 49, 107-17.

64. Wang, W.; Li, L.; Lin, W. L.; Dickson, D. W.; Petrucelli, L.; Zhang, T.; Wang, $X$. The ALS disease-associated mutant TDP-43 impairs mitochondrial dynamics and function in motor neurons. Hum. Mol. Genet. 2013, 22, 4706-19.

65. Onesto, E.; Colombrita, C.; Gumina, V.; Borghi, M. O.; Dusi, S.; Doretti, A.; Fagiolari, G.; Invernizzi, F.; Moggio, M.; Tiranti, V.; Silani, V.; Ratti, A. Gene-specific mitochondria dysfunctions in human TARDBP and C9ORF72 fibroblasts. Acta Neuropathol. Commun. 2016, 4, 47.

66. Buratti, E. TDP-43 post-translational modifications in health and disease. Expert Opin. Ther. Targets 2018, 22, 279-293.

67. Budini, M.; Baralle, F. E.; Buratti, E. Targeting TDP-43 in neurodegenerative diseases. Expert Opin. Ther. Targets 2014, 18, 617-32.

68. Gao, J.; Wang, L.; Huntley, M. L.; Perry, G.; Wang, X. Pathomechanisms of TDP-43 in neurodegeneration. J. Neurochem. 2018.

69. Nonaka, T.; Suzuki, G.; Tanaka, Y.; Kametani, F.; Hirai, S.; Okado, H.; Miyashita, T.; Saitoe, M.; Akiyama, H.; Masai, H.; Hasegawa, M. Phosphorylation of TAR DNA-binding protein of $43 \mathrm{kDa}$ (TDP-43) by truncated casein kinase 1delta triggers mislocalization and accumulation of TDP-43. J. Biol. Chem. 2016, 291, 547383.

70. Krach, F.; Batra, R.; Wheeler, E. C.; Vu, A. Q.; Wang, R.; Hutt, K.; Rabin, S. J.; Baughn, M. W.; Libby, R. T.; Diaz-Garcia, S.; Stauffer, J.; Pirie, E.; Saberi, S.; Rodriguez, M.; Madrigal, A. A.; Kohl, Z.; Winner, B.; Yeo, G. W.; Ravits, J. Transcriptome-pathology correlation identifies interplay between TDP-43 and the expression of its kinase CK1E in sporadic ALS. Acta Neuropathol. 2018, 136, 405-423.

71. Cozza, G.; Gianoncelli, A.; Montopoli, M.; Caparrotta, L.; Venerando, A.; Meggio, F.; Pinna, L. A.; Zagotto, G.; Moro, S. Identification of novel protein kinase CK1 delta (CK1ס) inhibitors through structure-based virtual screening. Biorg. Med. Chem. Lett. 2008, 18, 5672-5675.

72. Salado, I. G.; Redondo, M.; Bello, M. L.; Perez, C.; Liachko, N. F.; Kraemer, B. C.; Miguel, L.; Lecourtois, M.; Gil, C.; Martinez, A.; Perez, D. I. Protein kinase CK1 inhibitors as new potential drugs for amyotrophic lateral sclerosis. J. Med. Chem. 2014, 57, 2755-72.

73. Alquezar, C.; Salado, I. G.; de la Encarnación, A.; Pérez, D. I.; Moreno, F.; Gil, C.; de Munain, A. L.; Martínez, A.; Martín-Requero, Á. Targeting TDP-43 
phosphorylation by Casein Kinase-1ס inhibitors: a novel strategy for the treatment of frontotemporal dementia. Mol. Neurodegener. 2016, 11, 36.

74. Posa, D.; Martinez-Gonzalez, L.; Bartolome, F.; Nagaraj, S.; Porras, G.; Martinez, A.; Martin-Requero, A. Recapitulation of pathological TDP-43 features in immortalized lymphocytes from sporadic ALS patients. Mol. Neurobiol. 2018.

75. Joshi, K.; Goyal, S.; Grover, S.; Jamal, S.; Singh, A.; Dhar, P.; Grover, A. Novel group-based QSAR and combinatorial design of CK-1ठ inhibitors as neuroprotective agents. BMC Bioinformatics 2016, 17, 515-515.

76. Benek, O.; Hroch, L.; Aitken, L.; Gunn-Moore, F.; Vinklarova, L.; Kuca, K.; Perez, D. I.; Perez, C.; Martinez, A.; Fisar, Z.; Musilek, K. 1-(Benzo[d]thiazol-2-yl)-3phenylureas as dual inhibitors of casein kinase 1 and $A B A D$ enzymes for treatment of neurodegenerative disorders. J. Enzyme Inhib. Med. Chem. 2018, 33, 665-670.

77. Menichincheri, M.; Bargiotti, A.; Berthelsen, J.; Bertrand, J. A.; Bossi, R.; Ciavolella, A.; Cirla, A.; Cristiani, C.; Croci, V.; D’Alessio, R.; Fasolini, M.; Fiorentini, F.; Forte, B.; Isacchi, A.; Martina, K.; Molinari, A.; Montagnoli, A.; Orsini, P.; Orzi, F.; Pesenti, E.; Pezzetta, D.; Pillan, A.; Poggesi, I.; Roletto, F.; Scolaro, A.; Tatò, M.; Tibolla, M.; Valsasina, B.; Varasi, M.; Volpi, D.; Santocanale, C.; Vanotti, E. First Cdc7 Kinase Inhibitors: Pyrrolopyridinones as Potent and Orally Active Antitumor Agents. 2. Lead Discovery. J. Med. Chem. 2009, 52, 293-307.

78. Taylor, L. M.; McMillan, P. J.; Liachko, N. F.; Strovas, T. J.; Ghetti, B.; Bird, T. D.; Keene, C. D.; Kraemer, B. C. Pathological phosphorylation of tau and TDP-43 by TTBK1 and TTBK2 drives neurodegeneration. Mol. Neurodegener. 2018, 13, 7.

79. Nozal, V.; Martinez, A. Tau Tubulin Kinase 1 (TTBK1), a new player in the fight against neurodegenerative diseases. Eur. J. Med. Chem. 2019, 161, 39-47.

80. Xue, Y.; Wan, P. T.; Hillertz, P.; Schweikart, F.; Zhao, Y.; Wissler, L.; Dekker, N. X-ray structural analysis of tau-tubulin kinase 1 and its interactions with small molecular inhibitors. ChemMedChem 2013, 8, 1846-54.

81. Kiefer, S. E.; Chang, C. J.; Kimura, S. R.; Gao, M.; Xie, D.; Zhang, Y.; Zhang, G.; Gill, M. B.; Mastalerz, H.; Thompson, L. A.; Cacace, A. M.; Sheriff, S. The structure of human tau-tubulin kinase 1 both in the apo form and in complex with an inhibitor. Acta Crystallogr. F. Struct. Biol. Commun. 2014, 70, 173-81.

82. Heyburn, L.; Hebron, M. L.; Smith, J.; Winston, C.; Bechara, J.; Li, Z.; Lonskaya, I.; Burns, M. P.; Harris, B. T.; Moussa, C. E. Tyrosine kinase inhibition reverses TDP-43 effects on synaptic protein expression, astrocytic function and amino acid dis-homeostasis. J. Neurochem. 2016, 139, 610-623.

83. Imamura, K.; Izumi, Y.; Watanabe, A.; Tsukita, K.; Woltjen, K.; Yamamoto, T.; Hotta, A.; Kondo, T.; Kitaoka, S.; Ohta, A.; Tanaka, A.; Watanabe, D.; Morita, M.; Takuma, H.; Tamaoka, A.; Kunath, T.; Wray, S.; Furuya, H.; Era, T.; Makioka, K.; Okamoto, K.; Fujisawa, T.; Nishitoh, H.; Homma, K.; Ichijo, H.; Julien, J. P.; Obata, N.; Hosokawa, M.; Akiyama, H.; Kaneko, S.; Ayaki, T.; Ito, H.; Kaji, R.; Takahashi, R.; Yamanaka, S.; Inoue, H. The Src/c-Abl pathway is a potential therapeutic target in amyotrophic lateral sclerosis. Sci. Transl. Med. 2017, 9.

84. Boyd, J. D.; Lee, P.; Feiler, M. S.; Zauur, N.; Liu, M.; Concannon, J.; Ebata, A.; Wolozin, B.; Glicksman, M. A. A high-content screen identifies novel compounds that inhibit stress-induced TDP-43 cellular aggregation and associated cytotoxicity. J. Biomol. Screen. 2014, 19, 44-56.

85. Liu-Yesucevitz, L.; Bilgutay, A.; Zhang, Y. J.; Vanderweyde, T.; Citro, A.; Mehta, T.; Zaarur, N.; McKee, A.; Bowser, R.; Sherman, M.; Petrucelli, L.; Wolozin, 
B. Tar DNA binding protein-43 (TDP-43) associates with stress granules: analysis of cultured cells and pathological brain tissue. PLoS One 2010, 5, e13250.

86. Caccamo, A.; Shaw, D. M.; Guarino, F.; Messina, A.; Walker, A. W.; Oddo, S. Reduced protein turnover mediates functional deficits in transgenic mice expressing the $25 \mathrm{kDa}$ C-terminal fragment of TDP-43. Hum. Mol. Genet. 2015, 24, 4625-35.

87. Li, J.; Kim, S. G.; Blenis, J. Rapamycin: one drug, many effects. Cell Metab. 2014, 19, 373-379.

88. Kim, Y. C.; Guan, K.-L. mTOR: a pharmacologic target for autophagy regulation. J. Clin. Invest. 2015, 125, 25-32.

89. Caccamo, A.; Majumder, S.; Deng, J. J.; Bai, Y.; Thornton, F. B.; Oddo, S. Rapamycin rescues TDP-43 mislocalization and the associated low molecular mass neurofilament instability. J. Biol. Chem. 2009, 284, 27416-24.

90. Wang, I. F.; Guo, B. S.; Liu, Y. C.; Wu, C. C.; Yang, C. H.; Tsai, K. J.; Shen, C. K. Autophagy activators rescue and alleviate pathogenesis of a mouse model with proteinopathies of the TAR DNA-binding protein 43. Proc. Natl. Acad. Sci. U. S. A. 2012, 109, 15024-9.

91. Cheng, C. W.; Lin, M. J.; Shen, C. K. Rapamycin alleviates pathogenesis of a new Drosophila model of ALS-TDP. J. Neurogenet. 2015, 29, 59-68.

92. Zhang, X.; Li, L.; Chen, S.; Yang, D.; Wang, Y.; Zhang, X.; Wang, Z.; Le, W. Rapamycin treatment augments motor neuron degeneration in SOD1(G93A) mouse model of amyotrophic lateral sclerosis. Autophagy 2011, 7, 412-25.

93. Wang, J.; Qi, Q.; Feng, Z.; Zhang, X.; Huang, B.; Chen, A.; Prestegarden, L.; Li, X.; Wang, J. Berberine induces autophagy in glioblastoma by targeting the AMPK/mTOR/ULK1-pathway. Oncotarget 2016, 7, 66944-66958.

94. Fan, X.; Wang, J.; Hou, J.; Lin, C.; Bensoussan, A.; Chang, D.; Liu, J.; Wang, B. Berberine alleviates ox-LDL induced inflammatory factors by up-regulation of autophagy via AMPK/mTOR signaling pathway. J. Transl. Med. 2015, 13, 92-92.

95. Wang, X.; Wang, R.; Xing, D.; Su, H.; Ma, C.; Ding, Y.; Du, L. Kinetic difference of berberine between hippocampus and plasma in rat after intravenous administration of Coptidis rhizoma extract. Life Sci. 2005, 77, 3058-67.

96. Chang, C. F.; Lee, Y. C.; Lee, K. H.; Lin, H. C.; Chen, C. L.; Shen, C. J.; Huang, C. C. Therapeutic effect of berberine on TDP-43-related pathogenesis in FTLD and ALS. J. Biomed. Sci. 2016, 23, 72.

97. Sardiello, M.; Palmieri, M.; di Ronza, A.; Medina, D. L.; Valenza, M.; Gennarino, V. A.; Di Malta, C.; Donaudy, F.; Embrione, V.; Polishchuk, R. S.; Banfi, S.; Parenti, G.; Cattaneo, E.; Ballabio, A. A gene network regulating lysosomal biogenesis and function. Science 2009, 325, 473-7.

98. Wang, Y.; Liu, F. T.; Wang, Y. X.; Guan, R. Y.; Chen, C.; Li, D. K.; Bu, L. L.; Song, J.; Yang, Y. J.; Dong, Y.; Chen, Y.; Wang, J. Autophagic modulation by trehalose reduces accumulation of TDP-43 in a cell model of amyotrophic lateral sclerosis via tfeb activation. Neurotox. Res. 2018, 34, 109-120.

99. Rusmini, P.; Cortese, K.; Crippa, V.; Cristofani, R.; Cicardi, M. E.; Ferrari, V.; Vezzoli, G.; Tedesco, B.; Meroni, M.; Messi, E.; Piccolella, M.; Galbiati, M.; Garre, M.; Morelli, E.; Vaccari, T.; Poletti, A. Trehalose induces autophagy via lysosomalmediated TFEB activation in models of motoneuron degeneration. Autophagy 2018, 121.

100. Holler, C. J.; Taylor, G.; McEachin, Z. T.; Deng, Q.; Watkins, W. J.; Hudson, K.; Easley, C. A.; Hu, W. T.; Hales, C. M.; Rossoll, W.; Bassell, G. J.; Kukar, T. 
Trehalose upregulates progranulin expression in human and mouse models of GRN haploinsufficiency: a novel therapeutic lead to treat frontotemporal dementia. Mol. Neurodegener. 2016, 11, 46-46.

101. Chen, Y.; Li, S.; Su, L.; Sheng, J.; Lv, W.; Chen, G.; Xu, Z. Association of progranulin polymorphism rs5848 with neurodegenerative diseases: a meta-analysis. J. Neurol. 2015, 262, 814-22.

102. Cenik, B.; Sephton, C. F.; Dewey, C. M.; Xian, X.; Wei, S.; Yu, K.; Niu, W.; Coppola, G.; Coughlin, S. E.; Lee, S. E.; Dries, D. R.; Almeida, S.; Geschwind, D. H.; Gao, F. B.; Miller, B. L.; Farese, R. V., Jr.; Posner, B. A.; Yu, G.; Herz, J. Suberoylanilide hydroxamic acid (vorinostat) up-regulates progranulin transcription: rational therapeutic approach to frontotemporal dementia. J. Biol. Chem. 2011, 286, 16101-8.

103. Haines, J. D.; Herbin, O.; de la Hera, B.; Vidaurre, O. G.; Moy, G. A.; Sun, Q.; Fung, H. Y.; Albrecht, S.; Alexandropoulos, K.; McCauley, D.; Chook, Y. M.; Kuhlmann, T.; Kidd, G. J.; Shacham, S.; Casaccia, P. Nuclear export inhibitors avert progression in preclinical models of inflammatory demyelination. Nat. Neurosci. 2015, 18, 511-20.

104. Archbold, H. C.; Jackson, K. L.; Arora, A.; Weskamp, K.; Tank, E. M. H.; Li, X.; Miguez, R.; Dayton, R. D.; Tamir, S.; Klein, R. L.; Barmada, S. J. TDP43 nuclear export and neurodegeneration in models of amyotrophic lateral sclerosis and frontotemporal dementia. Sci. Rep. 2018, 8, 4606.

105. Joardar, A.; Menzl, J.; Podolsky, T. C.; Manzo, E.; Estes, P. S.; Ashford, S.; Zarnescu, D. C. PPAR gamma activation is neuroprotective in a Drosophila model of ALS based on TDP-43. Hum. Mol. Genet. 2015, 24, 1741-54.

106. Dupuis, L.; Dengler, R.; Heneka, M. T.; Meyer, T.; Zierz, S.; Kassubek, J.; Fischer, W.; Steiner, F.; Lindauer, E.; Otto, M.; Dreyhaupt, J.; Grehl, T.; Hermann, A.; Winkler, A. S.; Bogdahn, U.; Benecke, R.; Schrank, B.; Wessig, C.; Grosskreutz, J.; Ludolph, A. C. A randomized, double blind, placebo-controlled trial of pioglitazone in combination with riluzole in amyotrophic lateral sclerosis. PLoS One 2012, 7, e37885.

107. Schlachetzki, J. C.; Saliba, S. W.; Oliveira, A. C. Studying neurodegenerative diseases in culture models. Braz. J. Psychiatry. 2013, 35 Suppl 2, S92-100.

108. Cashman, N. R.; Durham, H. D.; Blusztajn, J. K.; Oda, K.; Tabira, T.; Shaw, I. T.; Dahrouge, S.; Antel, J. P. Neuroblastoma x spinal cord (NSC) hybrid cell lines resemble developing motor neurons. Dev. Dyn. 1992, 194, 209-21.

109. Silani, V.; Braga, M.; Ciammola, A.; Cardin, V.; Scarlato, G. Motor neurones in culture as a model to study ALS. J. Neurol. 2000, 247 Suppl 1, I28-36.

110. Myszczynska, M.; Ferraiuolo, L. New in vitro models to study amyotrophic lateral sclerosis. Brain Pathol. 2016, 26, 258-65.

111. Dimos, J. T.; Rodolfa, K. T.; Niakan, K. K.; Weisenthal, L. M.; Mitsumoto, H.; Chung, W.; Croft, G. F.; Saphier, G.; Leibel, R.; Goland, R.; Wichterle, H.; Henderson, C. E.; Eggan, K. Induced pluripotent stem cells generated from patients with ALS can be differentiated into motor neurons. Science 2008, 321, 1218-21.

112. Lee, S.; Huang, E. J. Modeling ALS and FTD with iPSC-derived neurons. Brain Res. 2017, 1656, 88-97.

113. Egawa, N.; Kitaoka, S.; Tsukita, K.; Naitoh, M.; Takahashi, K.; Yamamoto, T.; Adachi, F.; Kondo, T.; Okita, K.; Asaka, I.; Aoi, T.; Watanabe, A.; Yamada, Y.; Morizane, A.; Takahashi, J.; Ayaki, T.; Ito, H.; Yoshikawa, K.; Yamawaki, S.; 
Suzuki, S.; Watanabe, D.; Hioki, H.; Kaneko, T.; Makioka, K.; Okamoto, K.; Takuma, H.; Tamaoka, A.; Hasegawa, K.; Nonaka, T.; Hasegawa, M.; Kawata, A.; Yoshida, M.; Nakahata, T.; Takahashi, R.; Marchetto, M. C.; Gage, F. H.; Yamanaka, S.; Inoue, H. Drug screening for ALS using patient-specific induced pluripotent stem cells. Sci. Transl. Med. 2012, 4, 145ra104.

114. Sreedharan, J.; Blair, I. P.; Tripathi, V. B.; Hu, X.; Vance, C.; Rogelj, B.; Ackerley, S.; Durnall, J. C.; Williams, K. L.; Buratti, E.; Baralle, F.; de Belleroche, J.; Mitchell, J. D.; Leigh, P. N.; Al-Chalabi, A.; Miller, C. C.; Nicholson, G.; Shaw, C. E. TDP-43 mutations in familial and sporadic amyotrophic lateral sclerosis. Science 2008, 319, 1668-72.

115. Liu, Y. C.; Chiang, P. M.; Tsai, K. J. Disease animal models of TDP-43 proteinopathy and their pre-clinical applications. Int. J. Mol. Sci. 2013, 14, 20079-111.

116. Vanden Broeck, L.; Callaerts, P.; Dermaut, B. TDP-43-mediated neurodegeneration: towards a loss-of-function hypothesis? Trends Mol. Med. 2014, 20, 66-71.

117. Esmaeili, M. A.; Panahi, M.; Yadav, S.; Hennings, L.; Kiaei, M. Premature death of TDP-43 (A315T) transgenic mice due to gastrointestinal complications prior to development of full neurological symptoms of amyotrophic lateral sclerosis. Int. J. Exp. Pathol. 2013, 94, 56-64.

118. Lutz, C. Mouse models of ALS: Past, present and future. Brain Res. 2018, 1693, 1-10.

119. Xu, Y. F.; Gendron, T. F.; Zhang, Y. J.; Lin, W. L.; D'Alton, S.; Sheng, H.; Casey, M. C.; Tong, J.; Knight, J.; Yu, X.; Rademakers, R.; Boylan, K.; Hutton, M.; McGowan, E.; Dickson, D. W.; Lewis, J.; Petrucelli, L. Wild-type human TDP-43 expression causes TDP-43 phosphorylation, mitochondrial aggregation, motor deficits, and early mortality in transgenic mice. J. Neurosci. 2010, 30, 10851-9.

120. Wegorzewska, I.; Bell, S.; Cairns, N. J.; Miller, T. M.; Baloh, R. H. TDP-43 mutant transgenic mice develop features of ALS and frontotemporal lobar degeneration. Proc. Natl. Acad. Sci. U. S. A. 2009, 106, 18809-14.

121. Xu, Y. F.; Zhang, Y. J.; Lin, W. L.; Cao, X.; Stetler, C.; Dickson, D. W.; Lewis, J.; Petrucelli, L. Expression of mutant TDP-43 induces neuronal dysfunction in transgenic mice. Mol. Neurodegener. 2011, 6, 73.

122. Wils, H.; Kleinberger, G.; Janssens, J.; Pereson, S.; Joris, G.; Cuijt, I.; Smits, V.; Ceuterick-de Groote, C.; Van Broeckhoven, C.; Kumar-Singh, S. TDP-43 transgenic mice develop spastic paralysis and neuronal inclusions characteristic of ALS and frontotemporal lobar degeneration. Proc. Natl. Acad. Sci. U. S. A. 2010, 107, 3858-63.

123. Coughlan, K. S.; Halang, L.; Woods, I.; Prehn, J. H. M. A high-fat jelly diet restores bioenergetic balance and extends lifespan in the presence of motor dysfunction and lumbar spinal cord motor neuron loss in TDP-43A315T mutant C57BL6/J mice. Dis. Model. Mech. 2016, 9, 1029-1037.

124. Roberson, E. D. Mouse models of frontotemporal dementia. Ann. Neurol. 2012, 72, 837-849.

125. White, M. A.; Kim, E.; Duffy, A.; Adalbert, R.; Phillips, B. U.; Peters, O. M.; Stephenson, J.; Yang, S.; Massenzio, F.; Lin, Z.; Andrews, S.; Segonds-Pichon, A.; Metterville, J.; Saksida, L. M.; Mead, R.; Ribchester, R. R.; Barhomi, Y.; Serre, T.; Coleman, M. P.; Fallon, J. R.; Bussey, T. J.; Brown, R. H.; Sreedharan, J. TDP-43 
gains function due to perturbed autoregulation in a Tardbp knock-in mouse model of ALS-FTD. Nat. Neurosci. 2018, 21, 552-563.

126. Wegorzewska, I.; Baloh, R. H. TDP-43-based animal models of neurodegeneration: new insights into ALS pathology and pathophysiology. Neurodegener. Dis. 2011, 8, 262-74.

127. Chou, C. C.; Zhang, Y.; Umoh, M. E.; Vaughan, S. W.; Lorenzini, I.; Liu, F.; Sayegh, M.; Donlin-Asp, P. G.; Chen, Y. H.; Duong, D. M.; Seyfried, N. T.; Powers, M. A.; Kukar, T.; Hales, C. M.; Gearing, M.; Cairns, N. J.; Boylan, K. B.; Dickson, D. W.; Rademakers, R.; Zhang, Y. J.; Petrucelli, L.; Sattler, R.; Zarnescu, D. C.; Glass, J. D.; Rossoll, W. TDP-43 pathology disrupts nuclear pore complexes and nucleocytoplasmic transport in ALS/FTD. Nat. Neurosci. 2018, 21, 228-239.

128. Walker, A. K.; Spiller, K. J.; Ge, G.; Zheng, A.; Xu, Y.; Zhou, M.; Tripathy, K.; Kwong, L. K.; Trojanowski, J. Q.; Lee, V. M. Functional recovery in new mouse models of ALS/FTLD after clearance of pathological cytoplasmic TDP-43. Acta Neuropathol. 2015, 130, 643-60.

129. Porta, S.; Xu, Y.; Restrepo, C. R.; Kwong, L. K.; Zhang, B.; Brown, H. J.; Lee, E. B.; Trojanowski, J. Q.; Lee, V. M. Patient-derived frontotemporal lobar degeneration brain extracts induce formation and spreading of TDP-43 pathology in vivo. Nat. commun. 2018, 9, 4220.

130. Perrin, S. Preclinical research: Make mouse studies work. Nature 2014, 507, 423-5. 


\section{Legends to the Figures}

Figure 1. Pathological TDP-43 modifications. Pathways involved in the pathology of TDP-43 proteinopathies. Genetic mutations, environmental stress and other factors result in postranlational modifications of TDP-43, such as hyperphosphorylation, protein cleavage and aggregates formation, together with cytosolic TDP-43 accumulation and impairment of UPS and autoghagy.

Figure 2. TDP-43 misfolding and protein degradation. Six different classes of misfolded TDP-43 and its mobility and vulnerability to degradation.

Figure 3. Chemical structure of kinase inhibitors that may recover TDP-43 homeostasis in cell models: A) benzothiazole compounds targeting $\mathrm{CK}-1$; B) CDC7 inhibitor PHA767491; C) TTBK1/2 inhibitors described in the literature; D) tyrosine kinase inhibitors

Figure 4. Chemical structure of some inhibitors of stress granule formation . Small molecules able to inhibit stress granule and TDP-43 inclusions formation are shown.

Figure 5. Autophagy modulators with efficacy in TDP-43 aggregation clearance. The chemical structure of some autophagy inducers are shown

Figure 6. Chemical structure of small molecules interfering with TDP-43 pathology. The chemical structure of Exportin-1 inhibitors, KPT-335, and KPT-350, and the PPAR $\gamma$ activator, pioglitazone, are shown

Figure 7. Diagram showing pharmacological interventions in TDP-43 pathology. The strategies of pharmacological intervention in pathological events involving TDP.43 include: targeting the increase in TDP-43 phosphorylation, the activity of UPS and autophay machinery, restoring the cytoplasmic TPP-43 accumulation, and preventing the formation of TDP.43-containing aggregates. In boxes, there is a list of the drugs interfering at different points of TDP-43 pathology. 


\section{Figure 1}

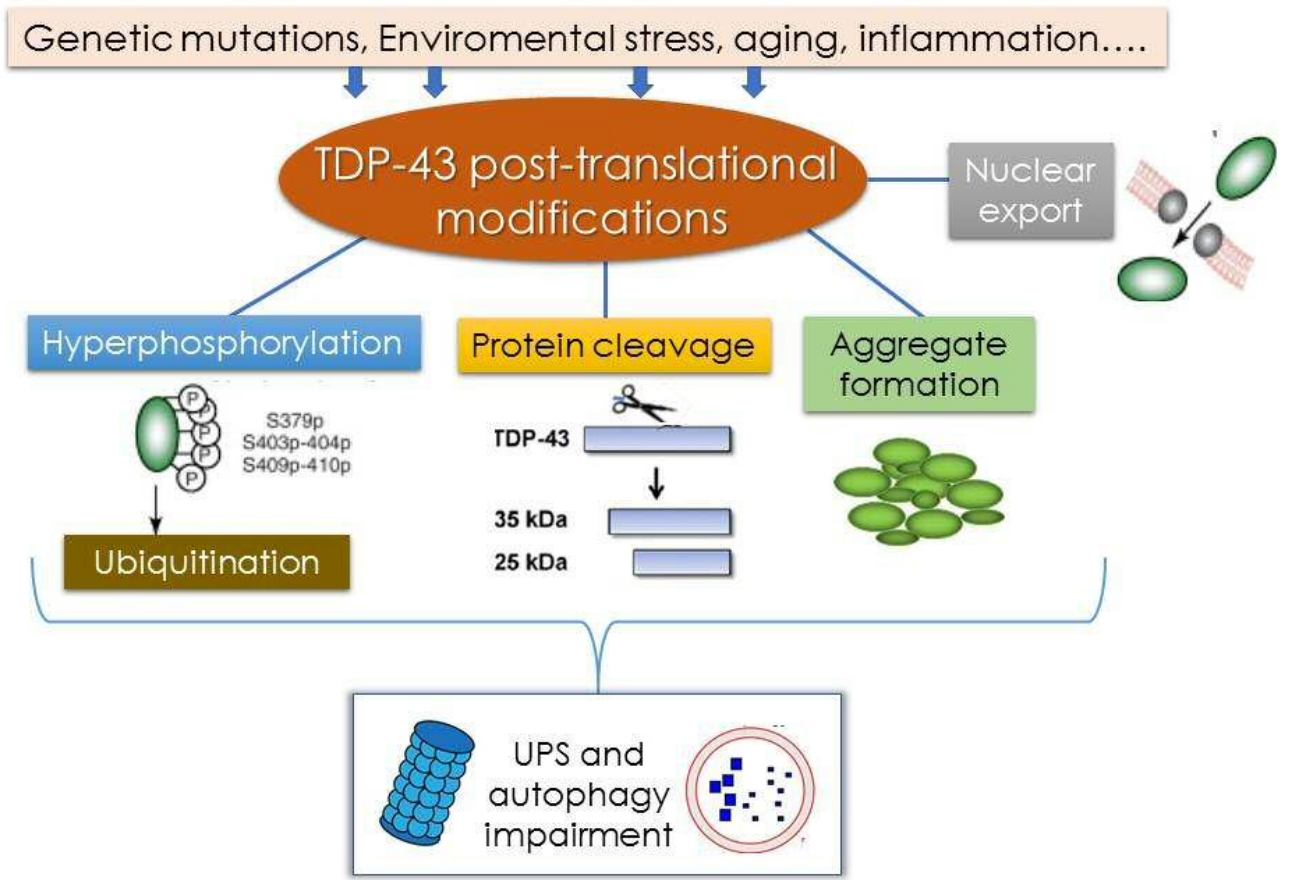




\section{Figure 2}

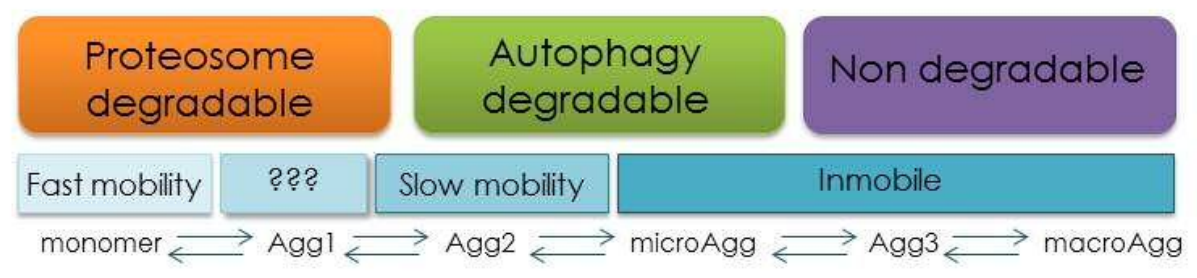


Figure 3

10 
A)<smiles>[R]c1ccc(CC(=O)Nc2nc3ccccc3s2)cc1</smiles>

$\mathrm{R}, \mathrm{R}^{\prime}=\mathrm{H}, \mathrm{CF}_{3}$, OMe, $\mathrm{F}, \mathrm{Cl}, \mathrm{Br}, \mathrm{OEt}$

$\mathrm{IC}_{50} \mathrm{CK} 1 \delta=17-0.01 \mu \mathrm{M}$<smiles>O=C(Cc1cccc(Cl)c1)Nc1nc2ccc(C(F)(F)F)cc2s1</smiles>

IGS-2.7

$\mathrm{IC}_{50} \mathrm{CK} 1 \delta=0.023 \pm 0.002 \mu \mathrm{M}$<smiles>CCc1cc(C2CC2)c2nc(NC(=O)Cc3cc(Cc4ccccc4)c(OC(=O)O)c(C4CC4)c3F)sc2c1</smiles><smiles>[R][R]c1ccc(NC(=O)Nc2nc3ccc([R])cc3s2)cc1</smiles>

$\mathrm{R}_{1}=\mathrm{F}, \mathrm{Cl} ; \mathrm{R}_{2}=\mathrm{OH}, \mathrm{Cl}, \mathrm{COOH}, \mathrm{OMe}, \mathrm{OPh}, \mathrm{COOEt}$, COOMe, NHCOMe

$\mathrm{IC}_{50} \mathrm{CK} 1 \delta=10-0.1 \mu \mathrm{M}$ $\mathrm{IC}_{50} \mathrm{CK} 1 \varepsilon=10-2 \mu \mathrm{M}$

B)<smiles>O=C1NCCc2[nH]c(-c3ccncc3)cc21</smiles>

PHA767491

$\mathrm{IC}_{50} \mathrm{CDC7}=10 \mathrm{nM}$<smiles>COCc1cc(C2CC2)c2nc(NC(=O)Cc3cc(Cc4ccccc4)c(OC(=O)O)c(C4CCCC5CCCCC54)c3F)sc2c1</smiles>

IGS-3.27

$\mathrm{IC}_{50} \mathrm{CK} 1 \delta=0.047 \pm 0.005 \mu \mathrm{M}$
C)<smiles>COc1cc2ncnc(Nc3cccc(O)c3)c2cc1OC</smiles>

$\mathrm{K}_{\mathrm{D}}$ TTBK1 $=0.24 \mu \mathrm{M}$<smiles>COC(=O)c1cc(Nc2ncnc3[nH]ccc23)ccc1Br</smiles>

$\mathrm{K}_{\mathrm{D}}$ TTBK1 $=4.1 \mu \mathrm{M}$

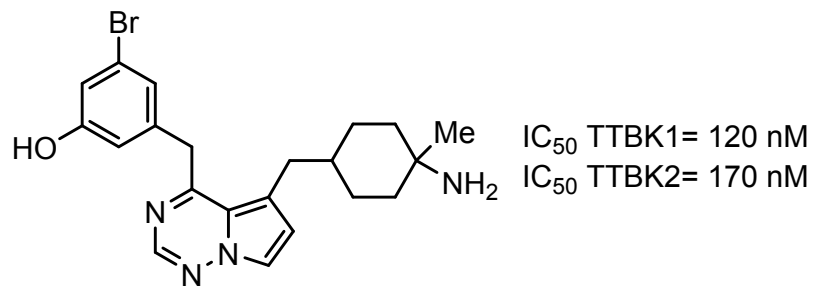

D)<smiles>Cc1cc(NC(=O)c2ccc(C)c(Nc3nccc(-c4cccnc4)n3)c2)cc(-n2cnc(C)c2)c1</smiles><smiles>COc1cc(Nc2c(C#N)cnc3cc(OCCCN4CCN(C)CC4)c(OC)cc23)c(Cl)cc1Cl</smiles> 
Figure 4<smiles>Cc1ccc(Cl)cc1NS(=O)(=O)c1c(C(=O)N2CCCC2)c(C)n(C)c1C</smiles>

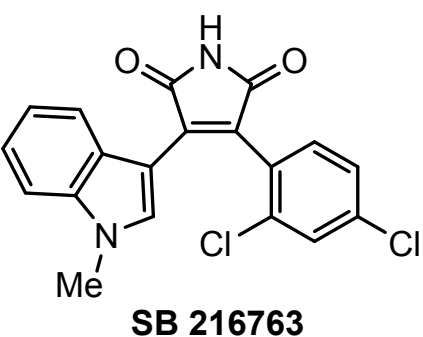<smiles>CC(C)(C)[R16](=O)(O)c1ccccc1C1=C(Nc2ccc(O)c(Cl)c2)C(=O)NC1=O</smiles><smiles>O=C1NC(=O)c2c1c1c3ccccc3[nH]c1c1[nH]c3ccccc3c21</smiles>

arcyriaflavin A<smiles>Cn1cnc2c(NCc3ccccc3)nc(NCCO)nc21</smiles>

olomoucine<smiles>CC1=NC2C(=O)C(Nc3ccc(C)cc3)=CC(=O)C2S1</smiles>

ryuvidine 


\section{Figure 5}

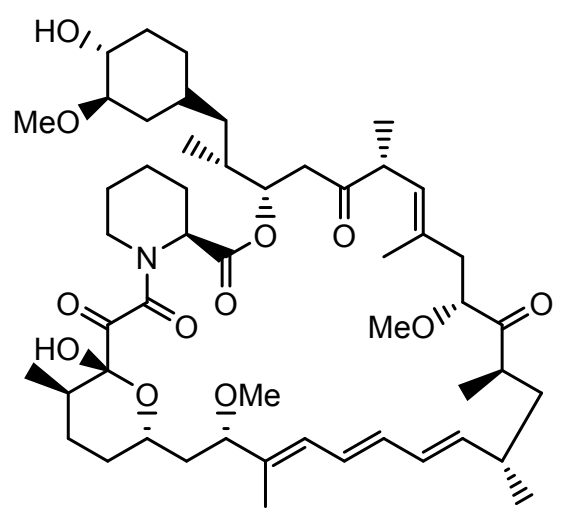

rapamycin<smiles></smiles><smiles>OC[C@H]1O[C@H](O[C@@H]2[C@@H](O)[C@H](O)[C@@H](O)[C@H](O)[C@H]2O)[C@H](O)[C@@H](O)[C@H]1O</smiles><smiles>O=C(CCCCCCC(=O)Nc1ccccc1)NO</smiles>

vorinostat 
Figure 6<smiles>CC(C)(C)C(=O)NNC(=O)/C=C\n1cnc(-c2cc(C(F)(F)F)cc(C(F)(F)F)c2)n1</smiles><smiles>CCOCCOCCc1ccc(OCCc2ccc(CC3SC(=O)NC3=O)cc2)cn1</smiles> 


\section{Figure 7}




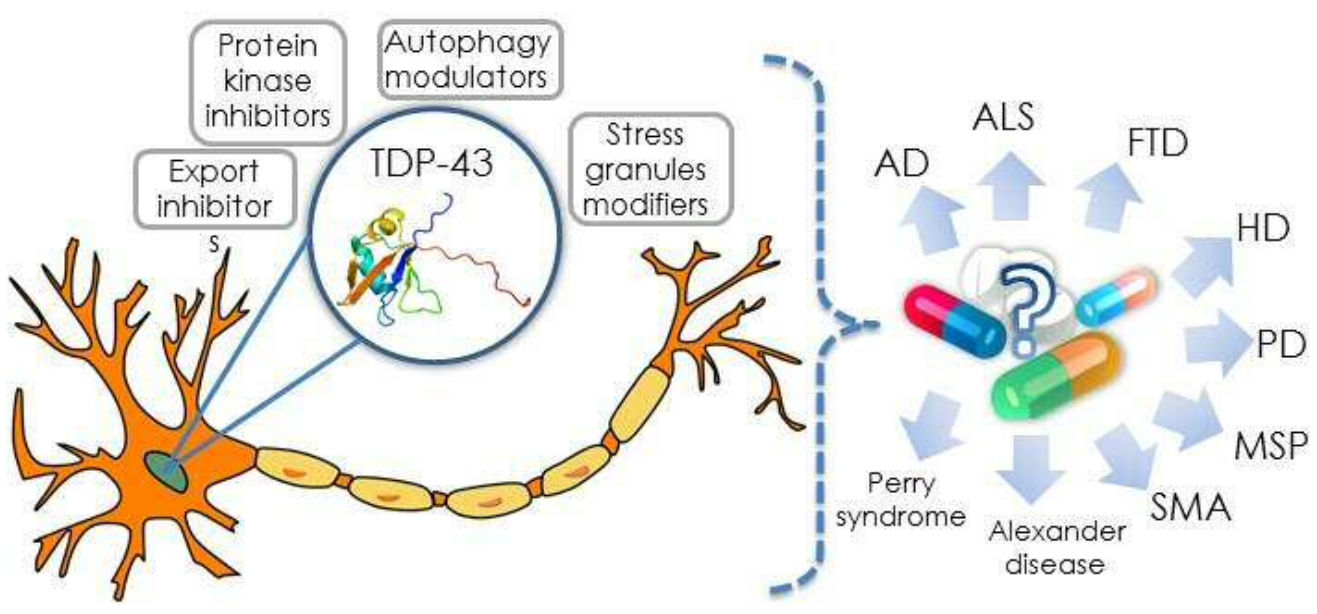


Genetic mutations, Enviromental stress, aging, inflammation..

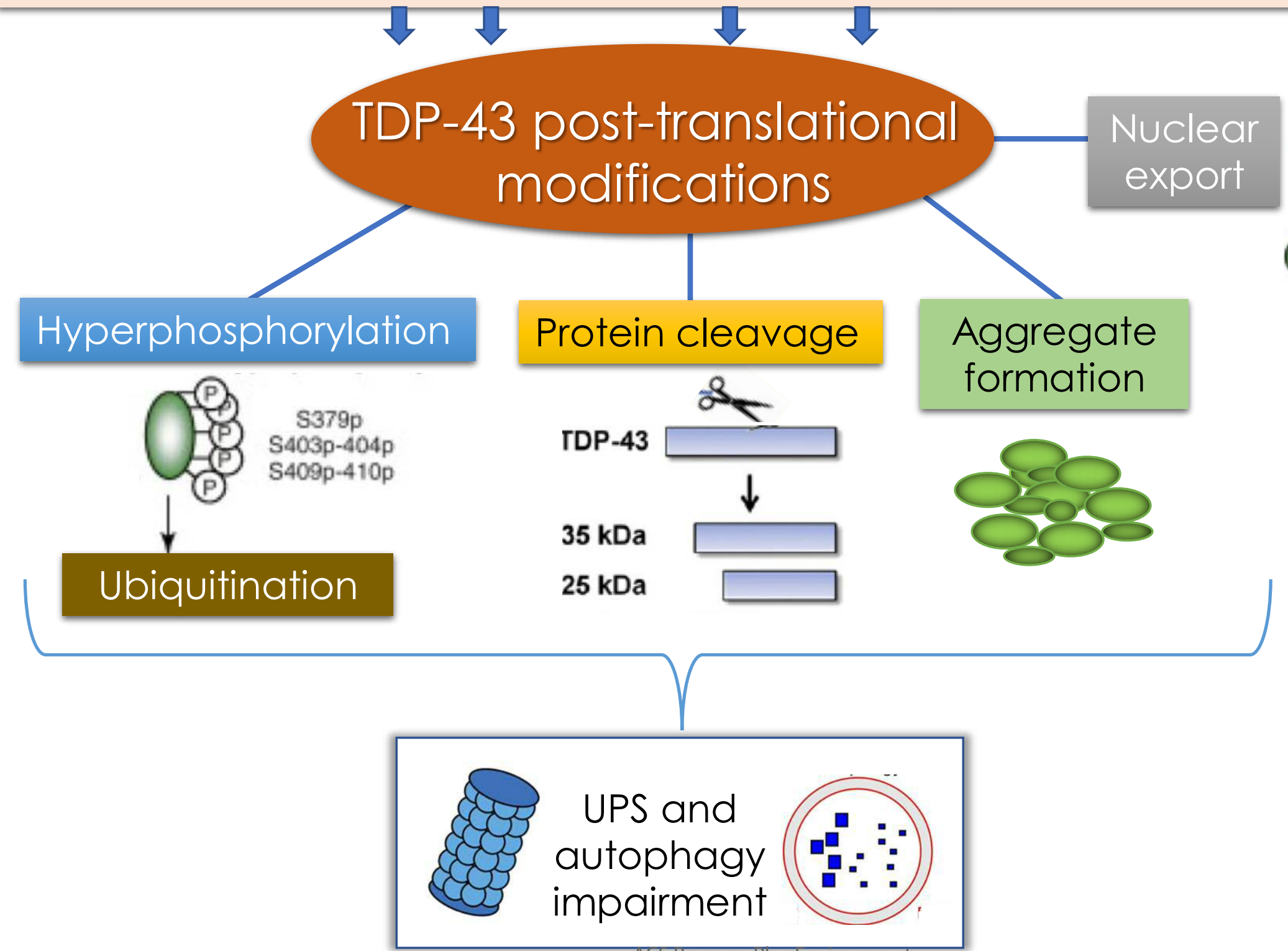




\section{Proteosome degradable \\ Autophagy degradable}

Non degradable

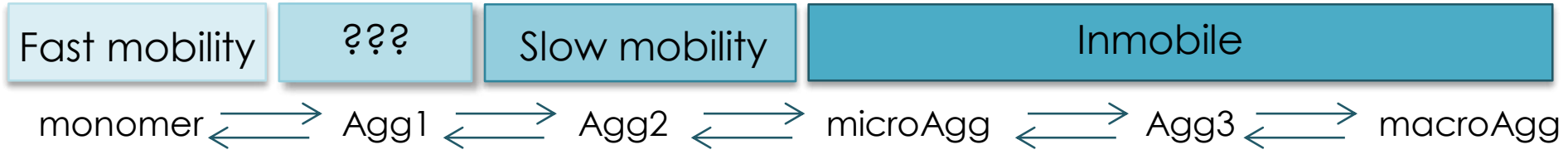


A)

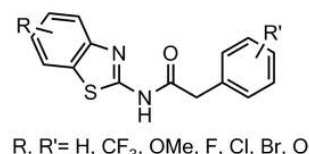

$\mathrm{R}, \mathrm{R}^{\prime}=\mathrm{H}, \mathrm{CF}_{3}, \mathrm{OMe}, \mathrm{F}, \mathrm{Cl}, \mathrm{Br}, \mathrm{OEt}$

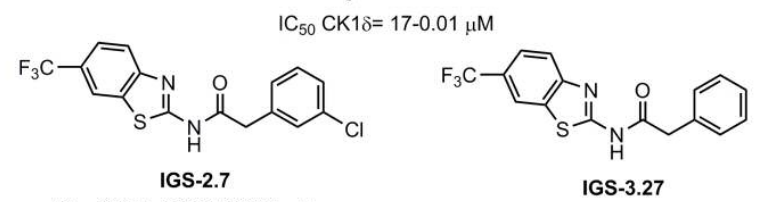

$\mathrm{IC}_{50} \mathrm{CK} 1 \delta=0.023 \pm 0.002 \mu \mathrm{M}$

$\mathrm{IC}_{50} \mathrm{CK} 1 \delta=0.047 \pm 0.005 \mu \mathrm{M}$
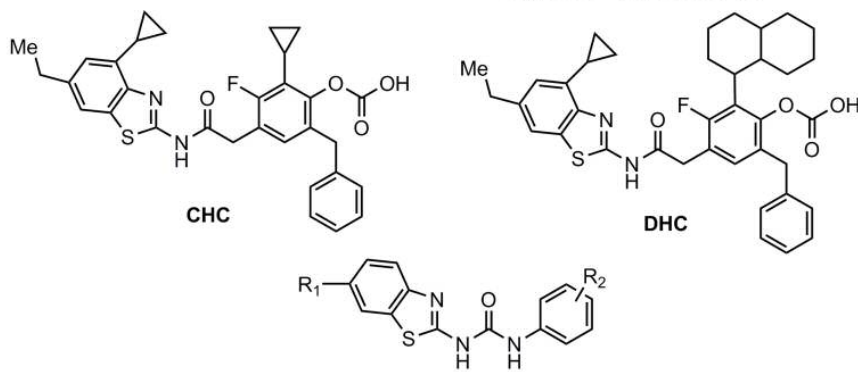

$\mathrm{R}_{1}=\mathrm{F}, \mathrm{Cl} ; \mathrm{R}_{2}=\mathrm{OH}, \mathrm{Cl}, \mathrm{COOH}, \mathrm{OMe}, \mathrm{OPh}, \mathrm{COOEt}, \mathrm{COOMe}, \mathrm{NHCOMe}$

$\mathrm{IC}_{50} \mathrm{CK} 1 \delta=10-0.1 \mu \mathrm{M}$

CK1 $\varepsilon_{\varepsilon}=10-2 \mu \mathrm{M}$

B)

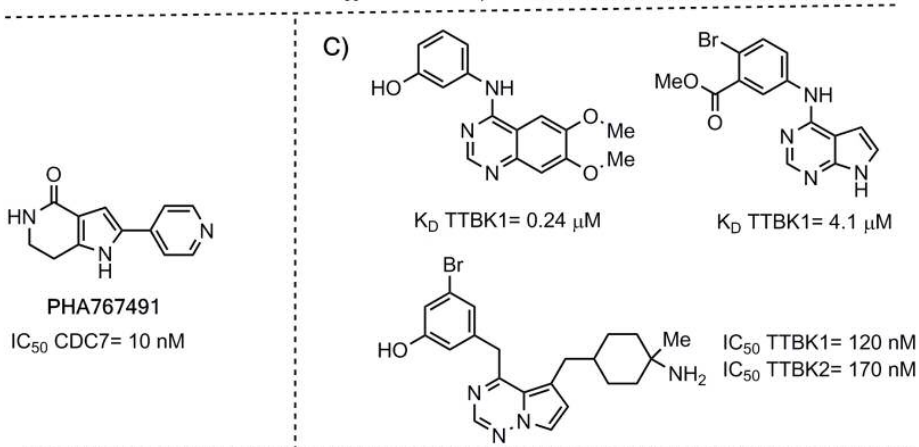

D)

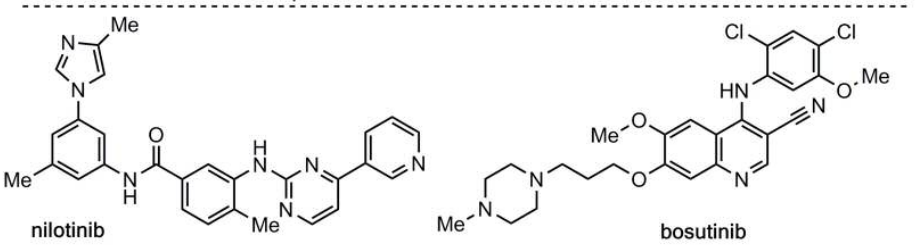

Figure 3

$171 \times 268 \mathrm{~mm}(300 \times 300 \mathrm{DPI})$ 


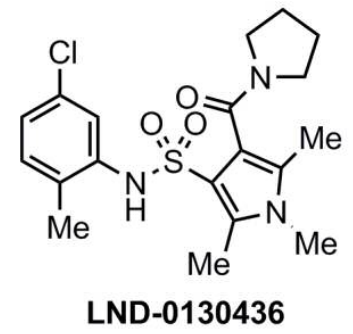<smiles>Cn1cc(C2=C(c3ccc(Cl)cc3Cl)C(=O)NC2=O)c2ccccc21</smiles>

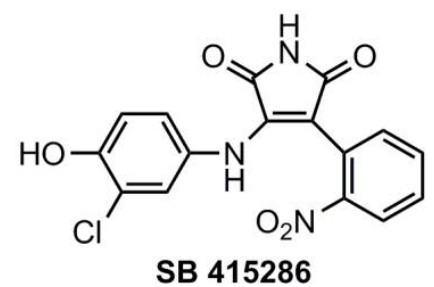<smiles>O=C1NC(=O)c2c1c1c3ccccc3[nH]c1c1[nH]c3ccccc3c21</smiles><smiles>Cn1cnc2c(NCc3ccccc3)nc(NCCO)nc21</smiles><smiles>CC1=NC2C(=O)C(Nc3ccc(C)cc3)=CC(=O)C2S1</smiles>

Figure 4 $145 \times 81 \mathrm{~mm}(300 \times 300$ DPI $)$ 


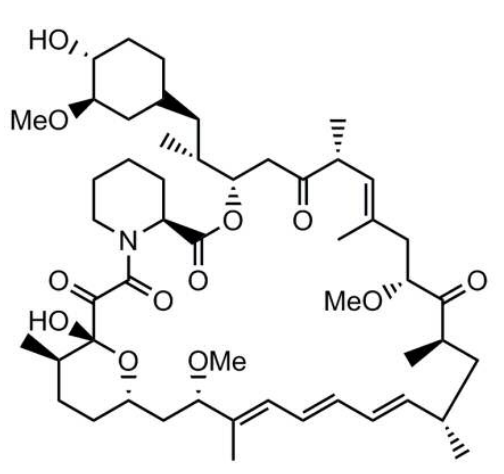

rapamycin

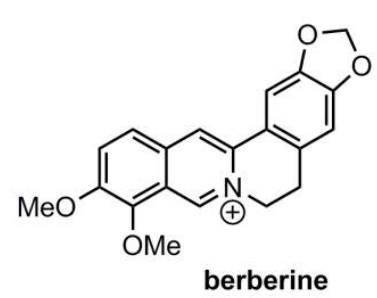

trehalose<smiles>CCOCCCCCCC(=O)Nc1ccccc1</smiles>

Figure 5

$167 \times 66 \mathrm{~mm}(300 \times 300$ DPI) 

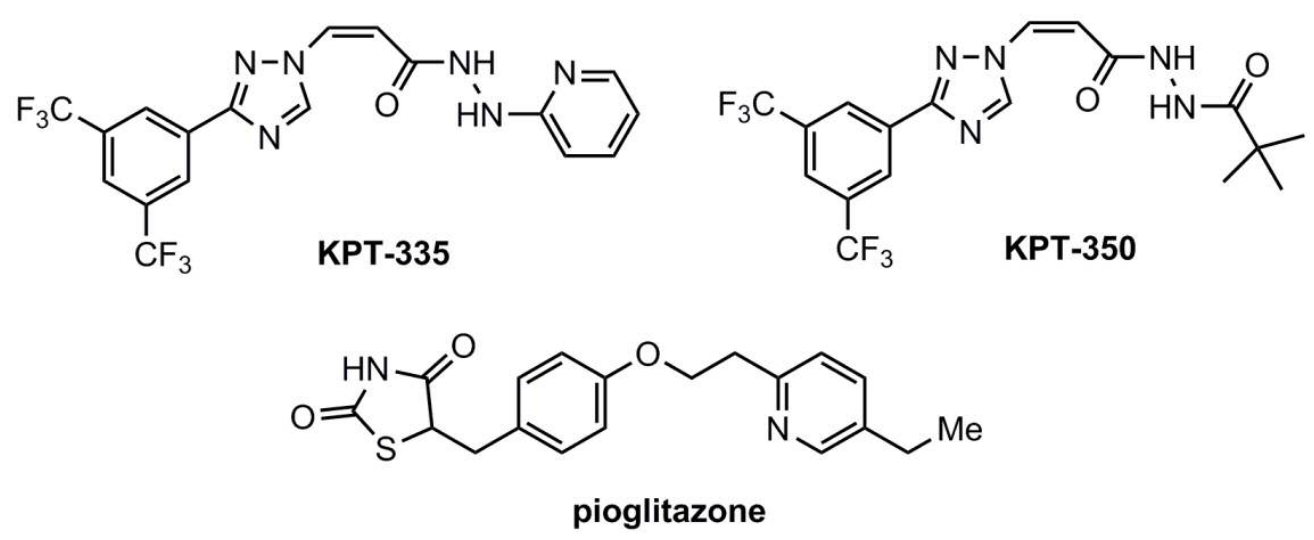

Figure 6

$138 \times 55 \mathrm{~mm}(300 \times 300$ DPI $)$ 
ACS Chemical Neuroscience

\section{Aging}

Prolonged stress

Inflamation

\section{Kinase inhibitors:}

CK-1 inhibitors CDC7 inhibitors GSK-3 $\beta$ inhibitors TTBK $1 / 2$ inhibitors ${ }_{7}^{5}$ Enviromental stress, genetic mutations

\section{Pioglitazone}

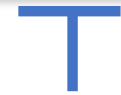

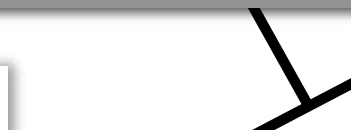

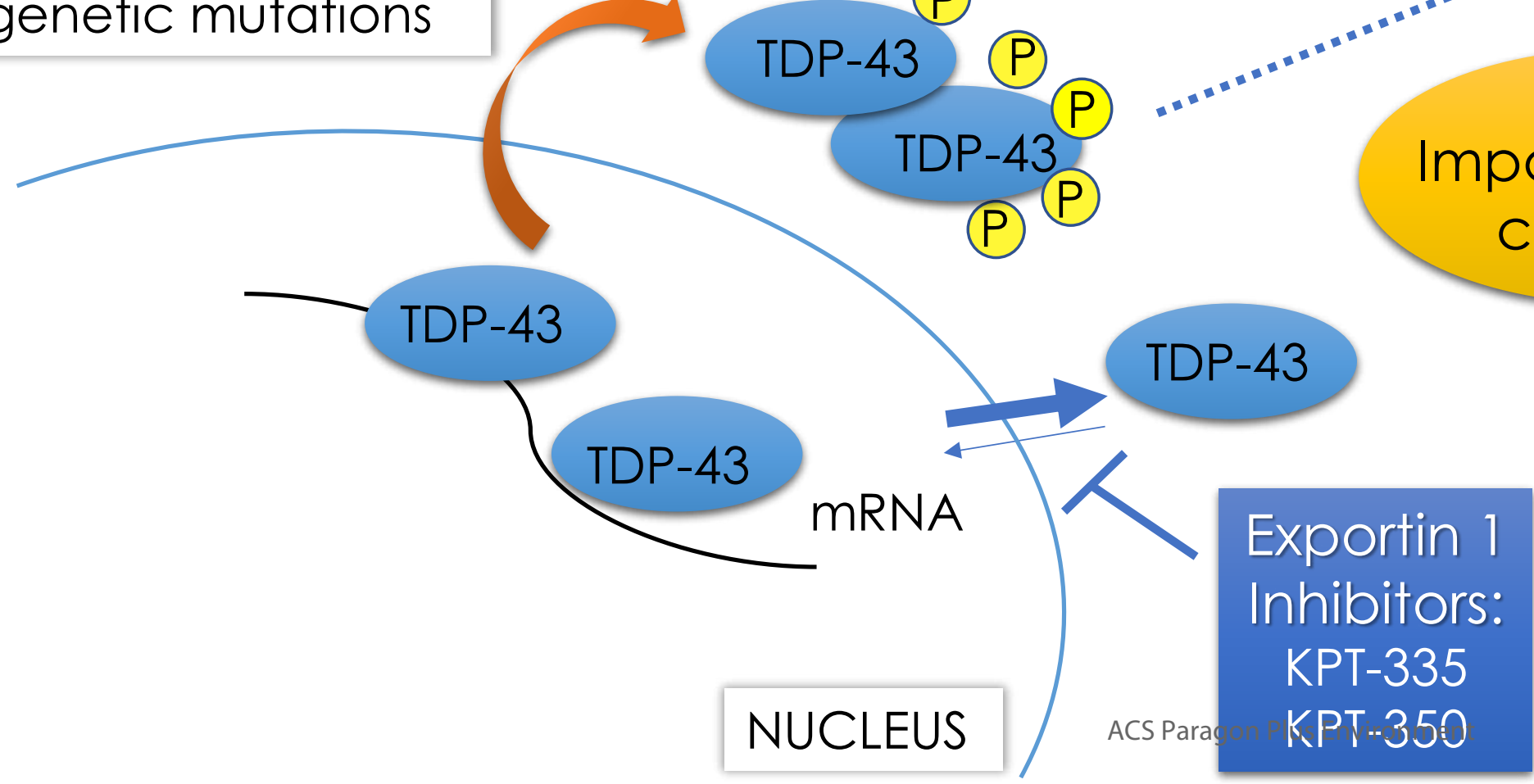

Progres: patho

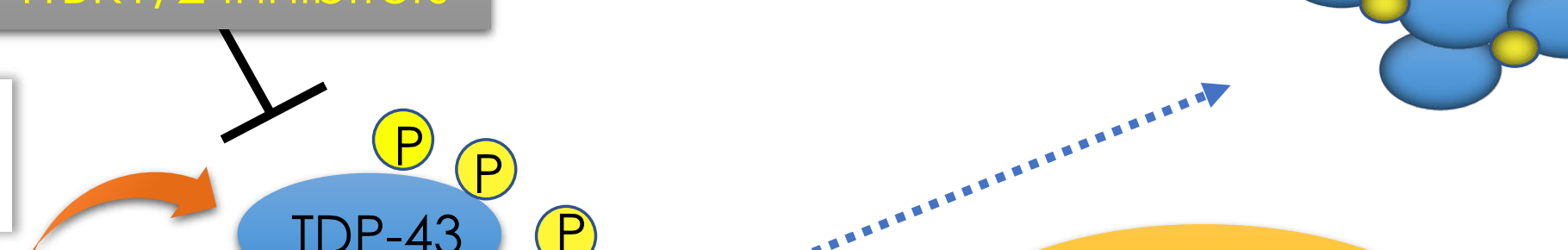

TDP-43 $P$

$P-43$ clearence 


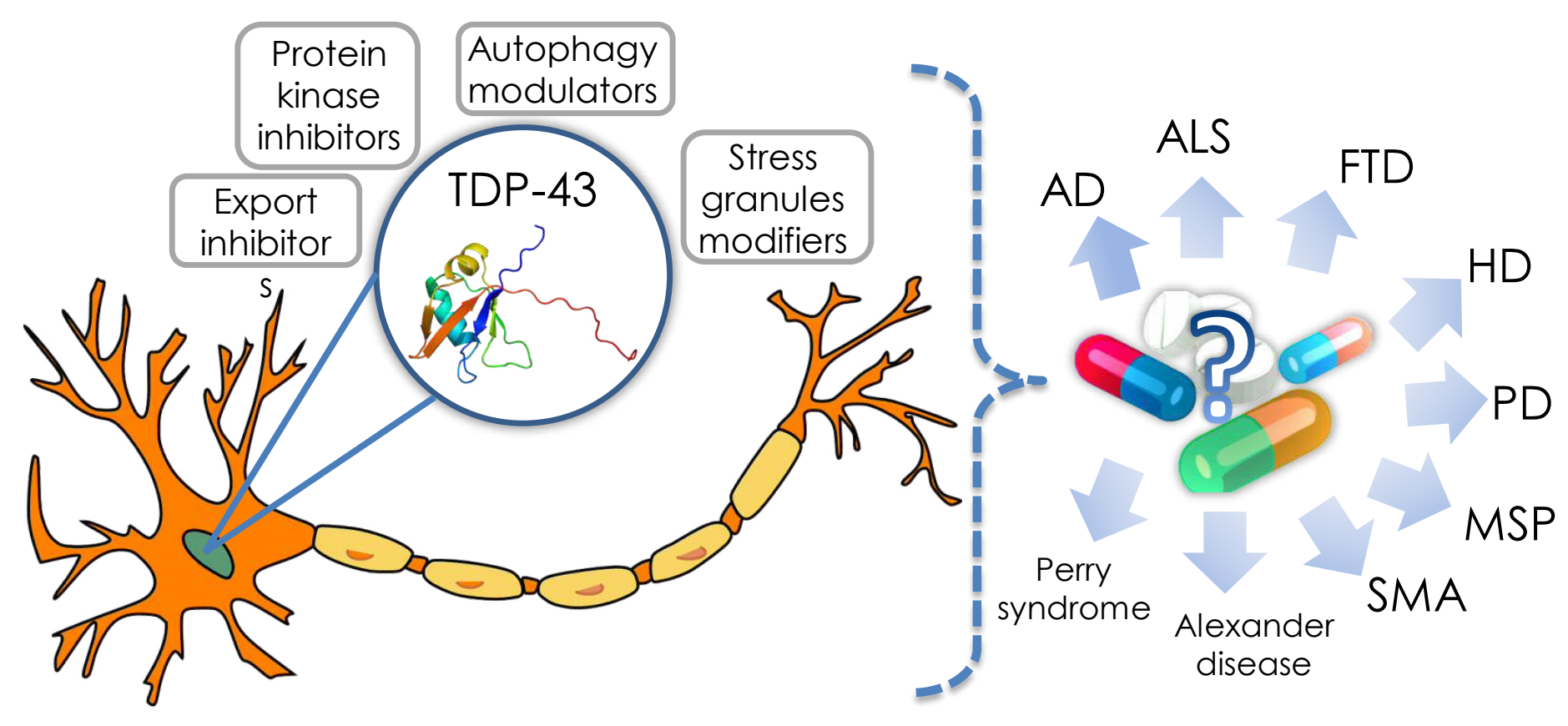

